\title{
Centros de origen, domesticación y diversidad genética de la ciruela mexicana, Spondias purpurea (Anacardiaceae)
}

\section{Origin, domestication, and genetic diversity centers of the Mexican plum, Spondias purpurea (Anacardiaceae)}

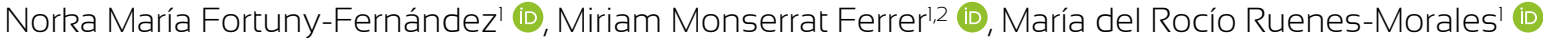

1 Universidad Autónoma de Yucatán, Campus de Ciencias Biológicas y Agropecuarias, Departamento de Conservación y Manejo de Recursos Naturales Tropicales, km 15.5 Carretera Mérida-Xmatkuil, Apdo. postal 4-116, Itzimná, 97143 Mérida, Yucatán, México.

2 Autor para la correspondencia: mferrer@correo.uady.mx

Citar como:

Fortuny-Fernández, N. M., M. M. Ferrer y M. del R. Ruenes-Morales. 2017. Centros de origen, domesticación y diversidad genética de la ciruela mexicana, Spondias purpurea (Anacardiaceae). Acta Botanica Mexicana 121: 7-38. DOI: http:// dx.doi.org/10.21829/abml21.2017.1289

Recibido: 2 de febrero de 2016 Revisado: 10 de octubre de 2016. Aceptado: 18 de mayo de 2017.

DOI: http://dx.doi.org/10.21829/abml21.2017.1289

\section{Resumen:}

Antecedentes y Objetivos: La identificación de poblaciones silvestres, con manejo agrícola o silvícola en los centros de origen y domesticación de plantas, es una acción importante en la conservación de los recursos fitogenéticos. Para identificar los centros de origen, domesticación y diversidad genética de Spondias purpurea en Mesoamérica se realizó un análisis filogeográfico de la especie.

Métodos: Se amplificó el marcador de DNAcp trnS-trnG para 66 accesiones del banco de germoplasma de $S$. purpurea y se obtuvieron las secuencias publicadas en GenBank para este marcador en el género Spondias. Las secuencias se agruparon en 54 poblaciones distribuidas de siete provincias biogeográficas de Mesoamérica, de acuerdo con las localidades de las colectas, y en tres categorías: silvestre, silvícola y agrícola.

Resultados clave: Se identificaron 38 haplotipos diferentes de los cuales 17 son exclusivos de S. purpurea, 12 a $S$. mombin, dos a $S$. radlkoferi y tres a $S$. testudinis; uno agrupa a $S$. purpurea y $S$. mombin, y uno a $S$. purpurea y $S$. radlkoferi. El análisis de contingencia anidada resultó en cinco grupos de haplotipos para las secuencias de todas las especies y otros cinco para los haplotipos de $S$. purpurea.

Conclusiones: El análisis de los resultados sugiere lo siguiente: 1) la falta de diferenciación entre los linajes podría deberse a hibridación entre las especies del género, lo que debe comprobarse con otros marcadores moleculares; 2) el centro de origen de $S$. purpurea se encuentra en la región de occidente de México (Jalisco, Nayarit, Michoacán); 3) el centro de origen y la región de Guatemala son centros de domesticación de $S$. purpurea; 4) existen ocho poblaciones que contienen haplotipos importantes para la conservación del germoplasma y tres provincias con diversidad nucleotídica importante.

Palabras clave: árboles frutales, filogeografía, red de haplotipos, Spondias mombin, Spondias radlkoferi, Spondias testudinis.

\section{ABSTRACT:}

Background and Aims: Conservation of wild and cultivated populations in which cultivated plants originated and were domesticated is an important management action for phytogenetic resources. The aim of this study was to identify the centers of origin, domestication and genetic diversity of Spondias purpurea in Mesoamerica through phylogeographic analyses.

Methods: The trnS-trn $G$ cpDNA marker was amplified for 66 accessions from the germplasm bank of $S$. purpurea and sequences from Genbank published for the genus Spondias were retrieved. Sequences were grouped in 54 populations from seven biogeographic provinces based on populations sampled, and, based on the management status of the specimens, in three categories: wild, forestry management and agricultural management.

Key results: In total, 38 different haplotypes were identified, 17 were exclusive for $S$. purpurea, 12 to $S$. mombin, two to $S$. radlkoferi, and three to S. testudinis; one grouped both $S$. purpurea and S. mombin, and one both $S$. purpurea and $S$. radlkoferi. Five groups of haplotypes were identified with the nested contingency analysis for all sequences of the genus, and another five for the $S$. purpurea sequences.

Conclusions: Analyses of the results suggest the following: 1) the lack of differentiation between the lineages may be due to hybridization between species of this genus, a hypothesis yet to be tested with other molecular markers; 2) the Western region of Mexico (Jalisco, Nayarit, Michoacán) is the center of origin; 3) the center of origin as well as Guatemala are domestication centers; 4) eight populations are particularly important for germplasm conservation programs due to the haplotypes they contain and three provinces with high nucleotide diversity.

Key words: fruit trees, haplotype network, phylogeography, Spondias mombin, Spondias radlkoferi, Spondias testudinis. 


\section{INTRODUCCIÓN}

Los conceptos de centro de origen de una especie, centro de domesticación y centro de diversidad genética juegan un papel importante en la priorización de áreas de conservación y manejo de recursos fitogenéticos. El centro de origen de una especie es el área geográfica en donde surge este taxon y desde el cual se dispersó y adquirió su distribución actual (Croizat et al., 1974). El centro de domesticación de una planta con manejo agrícola es aquella región en donde ocurrió la domesticación más temprana de las plantas silvestres que constituyen los sistemas de alimentación de los distintos pueblos (Engels et al., 2006; Boege, 2009). El centro de diversidad genética, por otra parte, es el sitio en donde existen tanto poblaciones silvestres como diferentes razas o variantes silvestres de una planta cultivada (Engels et al., 2006; Boege, 2009).

La domesticación y diversificación no son eventos históricos únicos que se desarrollen en un momento dado, sino que se trata de un largo proceso de dispersión y adaptación continua (Engels et al., 2006; Zeder et al., 2006; Boege, 2009; Piperno, 2011), a diferencia del origen de una especie que ocurre una sola vez, por lo que pueden existir varios centros de domesticación y diversidad genética para una especie cultivada. Los centros de origen, domesticación y diversidad genética son regiones importantes para la conservación del germoplasma original de las especies, porque los ancestros silvestres de las especies cultivadas son recursos fitogenéticos importantes que pueden contribuir a resolver problemas de alimentación presentes o futuros mediante planes de mejoramiento genético (Engels et al., 2006; Hernández-Verdugo et al., 2006; Boege, 2009; Jamnadass et al., 2009).

Adicionalmente, identificar los centros de domesticación y diversidad genética proporciona una información valiosa para entender cómo operaron los mecanismos de selección en plantas manejadas por el hombre (Zeder et al., 2006; Boege, 2009). Para establecer el centro de origen y los centros de domesticación de una especie, es necesario recopilar información utilizando evidencia paleoecológica, arqueológica y filogenética. Sin embargo, en los casos en los que no existen estudios paleoecológicos y/o registros arqueológicos, la información filogeográfica obtenida con marcadores moleculares puede ayudar a inferir tanto el centro de origen, como el número aproximado y sitio en donde ocurrió la domesticación de la especie (Jamnadass et al., 2009).

Uno de los enfoques más empleados para el estudio evolutivo de plantas domesticadas es el de la filogeografía (Schaal et al., 1998; Schaal y Olsen, 2000; Doebley et al., 2006; Engels et al., 2006; Jamnadass et al., 2009; Gross y Olsen, 2010), entendida como el estudio de los principios y procesos que rigen la distribución espacial de los linajes genealógicos dentro y entre especies (Avise, 2000). Los marcadores moleculares de DNA de cloroplasto son los que se han privilegiado en los estudios filogeográficos de las plantas, porque tienen mayor probabilidad de retener la información biogeográfica (Burger et al., 2008; Byrne y Hankinson, 2012; Nybom et al., 2014). En términos generales se asume que la diversidad genética de las especies cultivadas es menor que la de sus ancestros silvestres como consecuencia de la selección direccional y los cuellos de botella a que se someten las especies domesticadas. Sin embargo, existe evidencia de que tanto el flujo génico como la endogamia son inducidas por la domesticación. Por ejemplo, en plantas domesticadas en Mesoamérica, se propició el flujo génico a través de la dispersión deliberada de explantes de Stenocereus pruinosus (Otto ex Pfeiff.) Buxb. (Parra et al., 2012), o la endogamia por la selección de fenotipos que tienden a auto-polinizarse con mayor frecuencia en Polaskia chichipe (Gosselin) Backeb. (Otero-Arnaiz et al., 2003).

Mesoamérica se reconoce como uno de los principales centros de origen, domesticación y diversidad biológica de plantas cultivadas para la alimentación humana y animal (Vavilov, 1951; Harlan, 1971; Perales-Rivera y Aguirre-Rivera, 2008), en donde se domesticaron más de 100 especies de plantas (Hernández-Xolocotzi, 1998; Casas et al., 2007). La ciruela mexicana (Spondias purpurea L.) es una especie semi-domesticada, con niveles incipientes o intermedios de domesticación en la región Mesoamericana (Miller y Knouft, 2006; Ruenes-Morales et al., 2010) en la que las poblaciones cultivadas presentan una gran similitud genética con las poblaciones silvestres (Miller y Schaal, 
2006). Estudios filogeográficos previos sugieren dos probables centros de domesticación de esta especie, uno en las selvas bajas caducifolias del sur de Jalisco y Colima, y otro en las selvas bajas de la costa sur de El Salvador (Miller y Schaal, 2005). Sin embargo, se desconoce cuál es el centro de origen de esta especie, y si existen otros sitios adicionales de domesticación a los reportados por Miller y Schaal (2005). Ruenes-Morales et al. (2010) sugieren a la Península de Yucatán como otro sitio de domesticación ya que se encuentra una gran diversidad de formas cultivadas de esta especie. La falta de información sobre sitios adicionales de domesticación puede deberse en gran medida a la falta de inclusión de ejemplares de sitios donde la especie se distribuye en México y que no fueron incluidos en los trabajos de Miller y Schaal, 2005 y Miller, 2008. Al incrementarse el número de muestras representativas de diferentes regiones es posible detectar un número mayor de eventos de domesticación, como se demostró en el caso del frijol lima “ib” (Phaseolus lunatus L.) (Andueza-Noh, 2012).

Para este estudio nos preguntamos lo siguiente: ¿cuál es el centro de origen de Spondias purpurea y cuáles son sus diferentes centros de domesticación y diversidad genética en Mesoamérica? Para lograr tal objetivo, se realizó un análisis filogeográfico empleando el espaciador intergénico trnS-trnG del cloroplasto. Las secuencias analizadas se obtuvieron de colectas llevadas a cabo por las autoras, ejemplares del banco de germoplasma de la red de ciruela del Sistema Nacional de Recursos Fitogenéticos para la Alimentación y la Agricultura (SINAREFI, de aquí en adelante) y las reportadas por Miller y Schaal (2006). Para su análisis las secuencias se agruparon en 54 poblaciones que se presentan en nueve de las 14 regiones biogeográficas reconocidas por Espinosa-Organista et al. (2008) para la región Mesoamericana de México.

\section{Materiales y MÉtodos}

\section{Aislamiento, amplificación y secuenciación de DNA}

El DNA genómico se obtuvo de tejido foliar de 66 individuos de Spondias purpurea que constituyen la co- lección viva que es el reservorio de germoplasma de la Red Ciruela SINAREFI, que se encuentran albergada en el Centro Regional Universitario de la Península de Yucatán-Universidad Autónoma Chapingo (CRUPY-UACh, de aquí en adelante). Las colectas para conformar este banco de germoplasma se realizaron en cuatro regiones productoras de ciruela mexicana: Vertiente Pacífico Norte (Jalisco, Nayarit, Sinaloa y Sonora); Vertiente Pacífico Sur (Chiapas, Guerrero, Michoacán y Oaxaca), CentroSur (Morelos, Puebla y Veracruz), y Sureste de México (Campeche, Quintana Roo, Tabasco y Yucatán).

En cada una de las zonas se colectaron estacas ( $1 \mathrm{~m}$ de altura y $5 \mathrm{~cm}$ de diámetro) de individuos en pie para las principales variedades tradicionales de la ciruela mexicana y de las poblaciones silvestres remanentes en las zonas, de acuerdo a las indicaciones de informantes clave. Las estacas colectadas se mantienen en las instalaciones del CRUPY-UACh y un respaldo en la Universidad Autónoma de Yucatán (UADY) y la información de las colectas (nombre de la variedad, colector(es), geo-referencias, usos de la planta) se mantiene en la base de datos del banco de germoplasma a cargo del SINAREFI. La distribución de las accesiones corresponde al siguiente número de individuos por estado de procedencia: 12 de Campeche, 15 de Morelos, uno de Nayarit, uno de Michoacán, dos de Jalisco, uno de Sinaloa, dos de Tabasco, tres de Veracruz y 27 de Yucatán (Apéndice 1).

El DNA se extrajo de muestras de $250 \mathrm{mg}$ de tejido macerado con nitrógeno líquido empleando el método CTAB mini-prep modificado por Falcón y Valera (2007). La pureza del DNA genómico se evaluó mediante electroforesis en geles de agarosa borato de sodio a $0.8 \%$ (Brody y Kern, 2004) y se cuantificó usando un nano-espectrofotómetro (Nanodrop 1000 Spectophotometer Thermo Scientific, Wilmington, EUA).

La amplificación de las muestras de DNA genómico se realizó utilizando los cebadores reportados por Miller y Schaal (2005) para el marcador del espacio intergénico trnS-trn $G$ de DNA de cloroplasto. La reacción de PCR se hizo en $10 \mu \mathrm{l}$ que incluyen $1.5 \mu \mathrm{l}$ de DNA genómico (20 ng aproximadamente), $0.2 \mu 1$ del cebador senti- 
do $(35 \mathrm{mM})$ y $0.2 \mu \mathrm{l}$ del cebador contrasentido $(35 \mathrm{mM})$, $4.5 \mu \mathrm{l}$ de GoTaq $(2 \mathrm{X})$ y $3.6 \mu \mathrm{l}$ de $\mathrm{H}_{2} \mathrm{O}$. Las condiciones del termociclador (Techne-512, Barlorworld Scientific US, Burlington, EUA) para las PCR fueron las siguientes: desnaturalización $95^{\circ} \mathrm{C}$ por $2 \mathrm{~min}$; siete ciclos: $94^{\circ} \mathrm{C}$ por $45 \mathrm{~s}, 68^{\circ} \mathrm{C}$ por $45 \mathrm{~s}$ (disminuyendo $2{ }^{\circ} \mathrm{C}$ en cada ciclo), 72 ${ }^{\circ} \mathrm{C}$ por $60 \mathrm{~s}, 30$ ciclos, $94{ }^{\circ} \mathrm{C}$ por $45 \mathrm{~s}, 48{ }^{\circ} \mathrm{C}$ por $45 \mathrm{~s}, 72{ }^{\circ} \mathrm{C}$ por 60s y extensión final: $72{ }^{\circ} \mathrm{C}$ por $5 \mathrm{~min}$. El producto de la PCR se purificó con el kit Clean Wizard (Promega) siguiendo las instrucciones del proveedor. Los amplicones purificados fueron enviados a secuenciar a The Centre for Applied Genomics del Sick Kids Hospital de la ciudad de Toronto, Canadá (TCAG por sus siglas en inglés) en el que se emplea un secuenciador ABI 3730XL (Applied Biosystems, Carlsbad, EUA).

\section{Obtención de secuencias de GenBank}

Para tener una mayor representatividad de especímenes cultivados y silvestres de Spondias purpurea y de las especies hermanas $S$. mombin var. mombin, $S$. mombin var. globosa J.D. Mitch. \& D.C. Daly, S. radlkoferi Donn. Sm. y S. testudinis J.D. Mitch. \& D.C. Daly, se obtuvieron las secuencias publicadas en GenBank (2015), con una búsqueda en la base Nucleotide empleando las palabras clave "Spondias" y "trnS-trnG". La información de la localidad y el tipo de población de la que se obtuvo el ejemplar (silvestre, cerca viva, cerca natural, cultivado y parcelas) se recopiló en la base de datos Tropicos (TROPICOS, 2015) que alberga la información de las accesiones analizadas por Miller y Schaal (2005) que fueron depositadas en el herbario del Missouri Botanical Garden (MO). El tipo de manejo y la ubicación geográfica exacta para las colectas de Brasil no pudo obtenerse. La información de la ubicación geográfica, tipo de población, así como los números de accesiones del GenBank se reportan en el Apéndice 1.

Adicionalmente, se obtuvieron de GenBank: a) 51 secuencias de región intergénica trnA-trnH de DNAcp, 48 secuencias para siete especies del género Spondias, dos secuencias de la especie Pseudospondias microcarpa (A. Rich.) Engl. (Anacardiaceae) y una secuencia de Cana- rium balansae Engl. (Burseraceae), y b) 90 secuencias del marcador de DNA nuclear fosfoenol piruvato carboxilasa (PEPC): 51 secuencias para tres especies del género Spondias L. (Anacardiaceae) y 49 secuencias de 19 especies de Bursera Jacq. ex L. (Burseraceae) cuyas descripciones y número de accesión del GenBank se reportan en el Apéndice 2.

Agrupamiento de secuencias en provincias biogeográficas y por estatus de domesticación Cada uno de los ejemplares para los que se obtuvieron secuencias se asignó a una de 54 poblaciones de acuerdo con su distribución geográfica (latitud y longitud) y éstas fueron numeradas de 1 a 54 , de la distribución más austral hasta la más boreal (Apéndice 1). Las localidades de todos los ejemplares fueron mapeadas en Google Maps (figura no mostrada) con base en sus coordenadas geográficas, y ubicadas dentro de las áreas de distribución de las provincias biogeográficas modificadas por EspinosaOrganista et al. (2008). Las poblaciones de S. purpurea y las de sus especies hermanas están presentes en siete provincias biogeográficas: Eje Neovolcánico, Sierra Madre del Sur, Los Altos de Chiapas, Costa del Pacífico, Depresión del Balsas, Golfo de México y Península de Yucatán (Apéndice 1).

Los ejemplares se agruparon también por estatus de manejo empleando una categorización propuesta por Parra et al. (2012) quienes incluyen: 1) poblaciones silvestres, 2) manejo silvícola y 3) manejo agrícola. Estas tres categorías reconocen que los recursos fitogenéticos de Mesoamérica son colectados muchas veces de las poblaciones silvestres, mientras que en otros casos individuos silvestres son tolerados y mantenidos en vegetación primaria o secundaria, y otros tantos se cultivan en las parcelas o en los huertos de la casa donde se manejan con prácticas agrícolas (Casas et al., 2007; Parra et al., 2012). Los tres estatus de manejo para las poblaciones de ciruela corresponderían a 1) silvestres (en donde la ciruela puede o no ser recolectada), 2) manejo silvícola (toleradas en cercas vivas y cercas naturales) y 3) manejo agrícola (presentes en huertos familiares y cultivadas en parcelas). 
Cabe destacar que debido al muestreo dirigido realizado por Allison Miller (Miller y Schaal, 2005) y los colectores asociados a la red frutal ciruela del SINAREFI, en cada población todos los ejemplares tienen solo uno de los estatus de manejo.

\section{Alineación de las secuencias y prueba de neu- tralidad}

Las secuencias se alinearon usando el algoritmo ClustalX con el paquete MEGA 5 (Tamura et al., 2011). El alineamiento final se revisó de manera visual. Para comprobar la neutralidad en la evolución molecular de las secuencias de la región del cloroplasto $\operatorname{trnS}$-trnG, se usaron los estadísticos $D$ de Tajima y $D *$ de Fu y Li (Nei y Kumar, 2000) con el programa DnaSP 3.19 (Librado y Rozas, 2009).

\section{Diversidad genética en poblaciones, regiones biogeográficas y por tipos de manejo}

Los análisis de diversidad genética se realizaron solo para las secuencias de $S$. purpurea. Se registraron las frecuencias de los haplotipos para cada población, y los índices de diversidad haplotípica (Hd) y diversidad nucleotídica (p) se estimaron para cada provincia biogeográfica y para los datos agrupados en las tres categorías de manejo.

\section{Análisis filogeográfico de las secuencias}

El análisis filogeográfico para examinar las relaciones entre las áreas de distribución y los linajes genéticos de $S$. purpurea y sus especies hermanas se realizó obteniendo una red de haplotipos (Schaal et al., 1998; Avise, 2000). La red de haplotipos se obtuvo con la ayuda del programa TCS 1.21 (Clement et al., 2000) uniéndolos a todos hasta con un máximo de 70 diferencias. Los análisis de contingencia anidada para agrupar a los haplotipos (Templeton y Singt, 1993) se realizaron con el programa PopArt 1 (2014) en el módulo TCS. Se examinó la frecuencia de los diferentes haplotipos por especie y por poblaciones, así como tipo de manejo para cada grupo, con el fin de reconstruir la historia de los linajes genéticos de las cuatro especies de Spondias y para $S$. purpurea por separado.
Determinación de centros de origen, domesticación y diversidad genética

Se efectuaron análisis filogenéticos con: 1) región intergénica trnA-trnH de cloroplasto y 2) gen nuclear fosfoenol piruvato carboxilasa; para orientar la red de haplotipos de las especies de Spondias mesoamericanas. El alineamiento de las secuencias se realizó con el algoritmo ClustalW y una edición manual posterior con el programa MEGA 5.0 (Tamura et al., 2011), se obtuvieron dos alineamientos de longitud de 541 y 693 pares de bases, con 86 y 254 sitios variables, y 43 y 183 sitios parsimoniosamente informativos para la región intergénica $\operatorname{trn} A$-trnH de DNA de cloroplasto y para el gen fosfoenol piruvato carboxilasa, respectivamente. Los modelos de sustitución nucleotídica: 1) Tamura 3 parámetros para la región intergénica trnA-trnH de DNA de cloroplasto y 2) mismo modelo más distribución gamma para los sitios (0.88) para el gen fosfoenol piruvato carboxilasa se seleccionaron con base a los valores de criterios de información Bayesiana y de información Akaike obtenidos en el módulo Modeltest del programa MEGA 5.0 (Tamura et al., 2011).

Los cladogramas se optimizaron con el método de máxima verosimilitud; el soporte de los grupos formados se evaluó con 1000 repeticiones con un método de bootstrap y el programa MEGA 5.0 (Tamura et al., 2011). Los cladogramas se emplearon para identificar la(s) especie(s) hermana(s) de $S$. purpurea y, con base en esta información, orientar la red de haplotipos.

La población silvestre de $S$. purpurea en la que se unió el grupo de haplotipos de S. purpurea al grupo de haplotipos de la(s) especie(s) hermana(s) se consideró como el centro de origen de la especie.

Los centros de domesticación se identificaron como las regiones dentro de las provincias biogeográficas en las que estuvieron presentes individuos tanto de poblaciones silvestres como aquellas con manejo silvícola y/o agrícola y que se determinaron como un grupo de haplotipos con base en el análisis de contingencia.

Los centros de diversidad genética se identificaron como las poblaciones silvestres, con manejo silvícola y/o 
agrícola, en que existen varios haplotipos, así como las provincias en las que los índices de diversidad genética fueran más altos.

\section{Resultados y Discusión}

\section{Alineación de las secuencias y prueba de neu- tralidad}

Las secuencias alineadas para el espacio intergénico trnS$\operatorname{trn} G$ de DNA tuvieron una longitud de 592 pares de bases (pb), con 10 indels con longitudes de 1 a 219 pb, 43 sitios variables y 20 sitios parsimoniosamente informativos. El estadístico $D$ de Tajima tuvo un valor de -0.89 y el $D^{*}$ de $\mathrm{Fu}$ y Li -1.23. Ambos fueron no significativos $(\mathrm{P}>0.10)$, lo que indica neutralidad en la evolución molecular del marcador. Las pruebas de neutralidad en el estudio del marcador trnS-trnG en Spondias (Miller y Schaal, 2005) fue similar en este estudio, indicando que el marcador es neutral. Por ello, su uso para inferir las relaciones filoge- néticas entre los individuos evaluados, así como con otros marcadores de cloroplasto, es adecuado, como explican Shaw et al. (2007).

\section{Red de haplotipos y análisis de contingencia anidada}

De las 156 secuencias analizadas se identificaron 38 haplotipos diferentes para el marcador $\operatorname{trnS}$-trnG, 20 pertenecientes a $S$. purpurea, 12 a $S$. mombin (en sus variedades mombin y globosa), dos a $S$. radlkoferi y tres a $S$. testudinis (Cuadro 1). Los haplotipos se agruparon en seis grupos en la red anidada de las especies de Spondias (Figs. 1A, C). El grupo 1 contiene $80 \%$ de las secuencias: los 17 haplotipos asignados de manera exclusiva a Spondias purpurea, tres haplotipos en los que están representados $S$. purpurea y $S$. mombin var. mombin, uno con $S$. purpurea y $S$. radlkoferi y uno con S. mombin var. mombin y S. testudinis (Cuadro 1). Este grupo se distribuye en las poblaciones 1-2, 5, 9-10, 12-14, 16, 18-21, 24-31,

Cuadro 1: Anidamiento de haplotipos (Hapl.) del marcador trnS-trnG de Spondias spp. en los grupos determinados en el análisis de contingencia anidada para todas las especies de Spondias L. (Grupo 1) y solo para S. purpurea L. (Sp, Grupo 2). Los haplotipos exclusivos para Spondias mombin L. var. mombin (Smm), Spondias mombin L. var. globosa J.D. Mitch. \& D.C. Daly (Smg), S. radlkoferi Donn. Sm. (Sr) y S. testudinis J.D. Mitch. \& Daly (St) no se incluyeron en el análisis del grupo 2.

\begin{tabular}{cccccccccccc}
\hline Hapl. & Especie & $\begin{array}{c}\text { Grupos } \\
\text { red 1 }\end{array}$ & $\begin{array}{c}\text { Grupos } \\
\text { red 2 }\end{array}$ & Hapl. & Especie & $\begin{array}{c}\text { Grupos } \\
\text { red 1 }\end{array}$ & $\begin{array}{c}\text { Grupos } \\
\text { red 2 }\end{array}$ & Hapl. & Especie & $\begin{array}{c}\text { Grupos } \\
\text { red 1 }\end{array}$ & $\begin{array}{c}\text { Grupos } \\
\text { red 2 }\end{array}$ \\
\hline 1 & $\mathrm{Sp}$ & 1 & 1 & 14 & $\mathrm{Smm}, \mathrm{Sr}$ & 2 & - & 27 & $\mathrm{Smm}$ & 2 & - \\
2 & $\mathrm{Sp}$ & 1 & 2 & 15 & $\mathrm{Sp}$ & 1 & 2 & 28 & $\mathrm{Smm}$ & 2 & - \\
3 & $\mathrm{Sp}$ & 1 & 1 & 16 & $\mathrm{Sp}$ & 1 & 5 & 29 & $\mathrm{Smm}$ & 3 & - \\
4 & $\mathrm{Sp}$ & 1 & 2 & 17 & $\mathrm{Sp}, \mathrm{Smm}$ & 1 & 1 & 29 & $\mathrm{Smm}, \mathrm{Smg}$ & 3 & - \\
5 & $\mathrm{Sp}$ & 1 & 2 & 18 & $\mathrm{Sp}, \mathrm{Smm}$ & 1 & 3 & 30 & $\mathrm{Smm}$ & 3 & - \\
6 & $\mathrm{Sp}$ & 1 & 1 & 19 & $\mathrm{Sp}$ & 1 & 3 & 31 & $\mathrm{Smg}$ & 3 & - \\
7 & $\mathrm{Sp}$ & 1 & 2 & 20 & $\mathrm{Sp}$ & 1 & 1 & 32 & $\mathrm{Smg}$ & 3 & - \\
8 & $\mathrm{Sp}$ & 1 & 1 & 21 & $\mathrm{Sp}$ & 1 & 3 & 33 & $\mathrm{Smm}$ & 3 & - \\
9 & $\mathrm{Sp}$ & 1 & 1 & 22 & $\mathrm{Smm}$ & 1 & - & 34 & $\mathrm{Sr}$ & 4 & - \\
10 & $\mathrm{Sp}$ & 1 & 3 & 23 & $\mathrm{Smm}$ & 2 & - & 35 & $\mathrm{Sr}$ & 5 & - \\
11 & $\mathrm{Sp}$ & 1 & 3 & 24 & $\mathrm{Smm}$ & 2 & - & 36 & $\mathrm{St}$ & 1 & - \\
12 & $\mathrm{Sp}$ & 1 & 4 & 25 & $\mathrm{Smm}$ & 2 & - & 37 & $\mathrm{St}$ & 1 & - \\
13 & $\mathrm{Sp}, \mathrm{Sr}$ & 1 & 1 & 26 & $\mathrm{Smm}$ & 2 & - & 38 & $\mathrm{St}$ & 1 & - \\
\hline
\end{tabular}




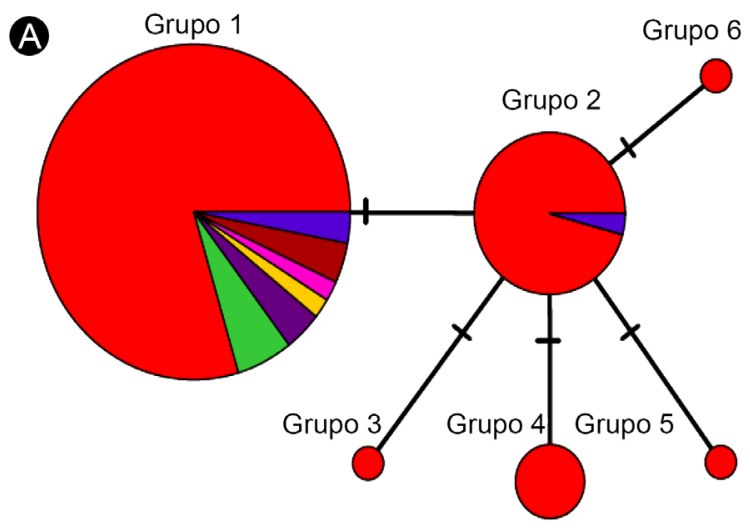

C
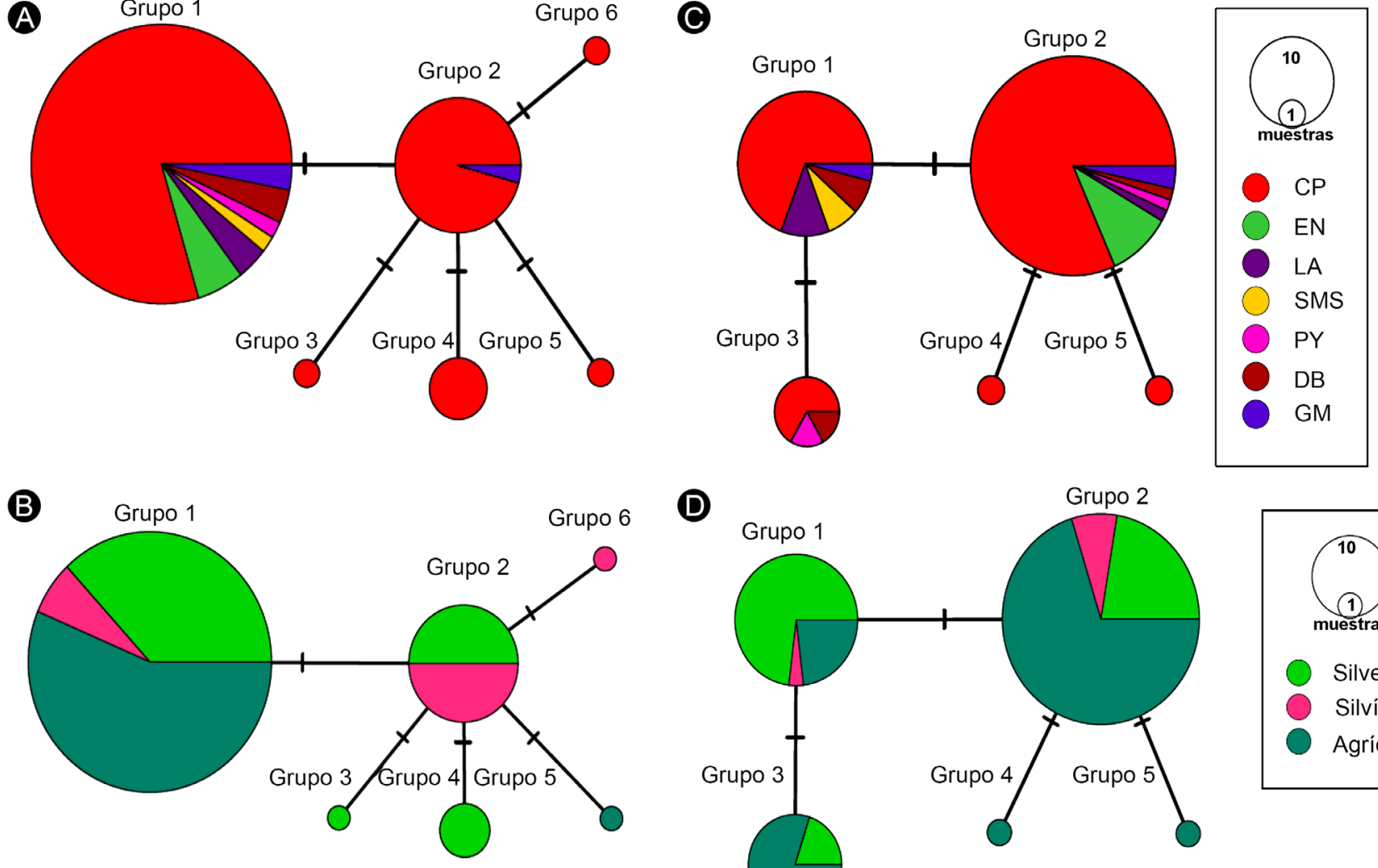

D
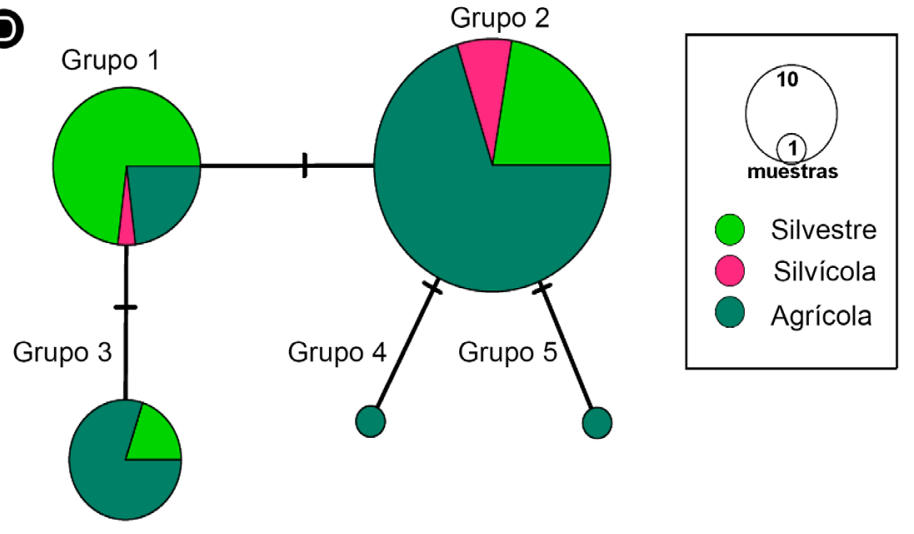

Figura 1: Análisis de contingencia anidada de la red de haplotipos. A, C. Spondias mombin L. var. mombin, S. mombin L. var. globosa J.D. Mitch. \& D.C. Daly, S. radlkoferi Donn. Sm., S. testudinis J.D. Mitch. \& Daly y $S$. purpurea L.; B, D. Spondias purpurea. A, B. distribución de los individuos en las siete provincias biogeográficas $(\mathrm{CP}=\mathrm{Costa}$ del Pacífico; $\mathrm{EN}=$ Eje Neovolcánico; $\mathrm{DB}=$ Depresión del Balsas; $\mathrm{SMS}=\mathrm{Sierra} \mathrm{Madre}$ del Sur; $\mathrm{GM}=\mathrm{Golfo}$ de México; LA=Los Altos de Chiapas; PY=Península de Yucatán); C, D. estatus de manejo de la población: silvestre, silvícola, manejo agrícola.

34-42, 44-54 y en todas las provincias biogeográficas y en las poblaciones de Brasil (Cuadro 2, Fig. 1A); 58\% de los ejemplares que pertenecen a este grupo tienen manejo agrícola, 35\% provienen de poblaciones silvestres y 7\% tienen manejo silvícola (Fig. 1B). Esta información sugiere que este grupo de haplotipos ha sido sometido a un proceso de domesticación y que no hay una asociación entre los diferentes haplotipos que le integran y la distribución geográfica de estos linajes.

El grupo 2 contiene 7 haplotipos de $S$. mombin var. mombin y uno que se registró en $S$. mombim var. mombin y $S$. radlkoferi (Cuadro 1); dos se distribuyen en las poblaciones 1-4, 6-8, 11-13, 15, 17, 22-23, 32-33, 37 y 43 que se ubican en las provincias de la Costa del Pacífico (en su porción sureste desde Oaxaca hasta Costa
Rica) y en el Golfo de México (Cuadro 2, Fig. 1A); 50\% de los ejemplares provienen de poblaciones silvestres y $50 \%$ de poblaciones con manejo silvícola (Cuadro 2 , Fig. 1B). Esto sugiere que $S$. mombin está en un estado incipiente de domesticación a lo largo de su distribución en Mesoamérica y que los haplotipos que tienen manejo silvícola están todavía presentes en las poblaciones silvestres.

El grupo 3 está integrado por dos haplotipos de $S$. mombin var. mombin, dos de S. mombin var. globosa y uno que comparten las dos variedades (Cuadro 1). Todas las accesiones de este grupo provienen de Brasil (Cuadro 2, Fig. 1A) y no se tiene información sobre el manejo de estas especies. El grupo 4 contiene una secuencia de $S$. mombin var. mombin colectada en la población 6 silvestre, 
Cuadro 2: Distribución de los haplotipos (Hapl.) de S. purpurea L., S. mombin L. var. mombin (Smm), S. mombin L. var. globosa J.D. Mitch. \& D.C. Daly (Smg) S. radlkoferi Donn. Sm. (Sr) y S. testudinis J.D. Mitch. \& Daly (St) en 54 poblaciones muestreadas (Pob) de provincia biogeográfica; más las de Brasil. Las secuencias se asignaron a 54 poblaciones de acuerdo con los datos de colecta presentados por Miller y Schaal (2006) y con las del banco de datos del SNICS-SINAREFI. CP=Costa del Pacífico; EN=Eje Neovolcánico; DB=Depresión del Balsas; SMS=Sierra Madre del Sur; GM=Golfo de México; LA=Los Altos de Chiapas; PY=Península de Yucatán. Se presenta además su estatus de manejo en la población (EM): silvestre (S), manejo silvícola (MS) y manejo agrícola (MA).

\begin{tabular}{|c|c|c|c|c|c|c|c|c|c|c|c|c|c|c|}
\hline Pob & $1 \mathrm{CP}$ & $2 \mathrm{CP}$ & $3 \mathrm{CP}$ & $4 \mathrm{CP}$ & $5 \mathrm{CP}$ & $6 \mathrm{CP}$ & $7 \mathrm{CP}$ & $8 \mathrm{CP}$ & $9 \mathrm{CP}$ & $10 \mathrm{CP}$ & $11 \mathrm{CP}$ & $12 \mathrm{CP}$ & $13 \mathrm{CP}$ & $14 \mathrm{CP}$ \\
\hline \multirow{4}{*}{$\begin{array}{l}\dot{\overrightarrow{0}} \\
\vec{\Xi}\end{array}$} & \multirow{4}{*}{ Smm14 } & 4 & \multirow[t]{4}{*}{ Smm14 } & \multirow[t]{4}{*}{ Smm14 } & 4 & Smm14 & $\mathrm{Smm} 23$ & Smm14 & 4 & 10 & Sr14 & 13 & 4 & 4 \\
\hline & & \multirow[t]{3}{*}{ Smm14 } & & & \multirow[t]{3}{*}{12} & $\mathrm{Smm} 27$ & $\mathrm{Smm} 23$ & Smm24 & & & \multirow[t]{3}{*}{$\operatorname{Sr} 35$} & Smm14 & 13 & \\
\hline & & & & & & $\mathrm{Smm} 28$ & Sr34 & $\mathrm{Smm} 25$ & & & & $\operatorname{Sr} 13$ & 17 & \\
\hline & & & & & & & & $\mathrm{Smm} 26$ & & & & & Smm17 & \\
\hline EM & MA & MA & MS & S & MA & S & S & MS & MA & MS & MS & S & S & S \\
\hline Pob & $15 \mathrm{CP}$ & $16 \mathrm{CP}$ & $17 \mathrm{CP}$ & $18 \mathrm{CP}$ & $19 \mathrm{CP}$ & $20 \mathrm{CP}$ & $21 \mathrm{CP}$ & $22 \mathrm{CP}$ & $23 \mathrm{CP}$ & $24 \mathrm{CP}$ & $25 \mathrm{CP}$ & $26 \mathrm{CP}$ & $27 \mathrm{CP}$ & $28 \mathrm{CP}$ \\
\hline \multirow{2}{*}{$\overline{\vec{z}}$} & $\mathrm{Smm} 4$ & 4 & $\mathrm{Smm} 18$ & 4 & 4 & 13 & 13 & Smm14 & Sr14 & 4 & 13 & 10 & 4 & 4 \\
\hline & Smm14 & 15 & & & & & 18 & & & & & & 13 & 13 \\
\hline EM & S & MA & MS & MA & MS & S & MA & MS & S & MA & S & MA & MA & MS \\
\hline \multirow[t]{2}{*}{ Pob } & $29 \mathrm{CP}$ & $30 \mathrm{CP}$ & $31 \mathrm{CP}$ & $32 \mathrm{CP}$ & $33 \mathrm{CP}$ & $34 \mathrm{CP}$ & $35 \mathrm{CP}$ & $36 \mathrm{CP}$ & $37 \mathrm{SMS}$ & $38 \mathrm{LA}$ & $39 \mathrm{LA}$ & $40 \mathrm{GM}$ & $41 \mathrm{EN}$ & $42 \mathrm{DB}$ \\
\hline & 19 & 4 & 4 & Smm14 & Smm14 & 4 & 4 & 4 & 4 & 4 & 6 & 4 & 1 & 7 \\
\hline \multirow{4}{*}{ 永 } & & 10 & & & & & 16 & & Smm14 & 13 & & & & 8 \\
\hline & & 13 & & & & & & & & & & & & 9 \\
\hline & & 20 & & & & & & & & & & & & 10 \\
\hline & & 21 & & & & & & & & & & & & \\
\hline EM & MA & $\mathrm{S}$ & MA & S & MA & MA & MA & MA & MA, S & S & S & MA & S & MA \\
\hline Pob & $43 \mathrm{GM}$ & $44 \mathrm{PY}$ & $45 \mathrm{EN}$ & $46 \mathrm{EN}$ & $47 \mathrm{CP}$ & $48 \mathrm{PY}$ & $49 \mathrm{CP}$ & $50 \mathrm{PY}$ & $51 \mathrm{PY}$ & $52 \mathrm{CP}$ & $53 \mathrm{CP}$ & $54 \mathrm{CP}$ & Brasil & Brasil \\
\hline \multirow{5}{*}{$\frac{\dot{\vec{a}}}{\vec{\Xi}}$} & \multirow[t]{5}{*}{ Smm14 } & \multirow[t]{5}{*}{4} & 2 & 5 & 2 & 11 & 1 & 4 & 4 & 4 & 1 & 4 & St36 & Smg 29 \\
\hline & & & 5 & & & & 2 & & & & 3 & & St37 & $\mathrm{Smm} 30$ \\
\hline & & & & & & & 4 & & & & & & St38Smm22 & Smm33 \\
\hline & & & & & & & & & & & & & Smm29 & Smg 31 \\
\hline & & & & & & & & & & & & & & Smg 32 \\
\hline EM & S & MA & MA & MA & S & MA & S & MA & MA, S & MA & S & MA & - & - \\
\hline
\end{tabular}

el grupo 5 una de $S$. radlkoferi de la población 7 con manejo agrícola y el grupo 6 una de $S$. radlkoferi de la población 11 con manejo silvícola (Cuadros 1, 2; Figs. 1A, B).

Los agrupamientos de haplotipos de las cinco especies estudiadas del género Spondias sugieren que los pobladores han introducido al cultivo un grupo de linajes genéticos presentes en poblaciones silvestres de S. purpurea (grupo 1) en menor proporción (Fig. 1B). Los linajes del grupo 1 han sido poco empleados en sistemas agroforestales donde se hace manejo silvícola (e.g. cercas vivas o vegetación natural o en ranchos para sombreado) (Fig. 1B). Las especies de S. mombin y $S$. radlkoferi son las que se prefieren para dichos usos, como lo sugieren las frecuencias similares de individuos de poblaciones silvestres y con manejo agrícola del grupo 2 (Fig. 1B). El agrupamiento de haplotipos representativos de la región sureste de la provincia de la Costa Pacífica y del Golfo de México (grupo 2), los de Brasil (grupo 3) y de los tres grupos con una secuencia única sugieren una diferenciación de los linajes genéticos que son particulares a la región sureste de Mesoamérica y Sudamérica (Fig. 1A). Por lo tanto, deben considerarse 
por separado en los esfuerzos de conservación de los recursos fitogenéticos del género Spondias.

El análisis de contingencia anidada para los haplotipos de Spondias purpurea permitió identificar 5 grupos en la red anidada (Figs. 1C, D). Tres de los cinco grupos de haplotipos agrupan más de cinco haplotipos, que en general tienen una amplia distribución en las diferentes poblaciones, mientras que dos grupos de haplotipos están confinados a la distribución más austral de la especie (Figs. 1B, D, 2). Las características de cada uno de estos grupos fueron útiles para la identificación de los centros de origen, de diversidad genética y domesticación como se discutirá en las siguientes secciones.

\section{Centro de origen de Spondias purpurea}

El análisis de la red de haplotipos completa nos indica que $S$. mombin y $S$. radlkoferi forman un grupo diferenciado de S. purpurea (Fig. 2). Los haplotipos del grupo S. purpurea se caracterizan por tener en su mayoría individuos de esta especie; sin embargo, los haplotipos 13 y 17 se presentan en individuos de $S$. radlkoferi y de $S$. mombin var. mombin, respectivamente (Cuadro 1). Estos datos son apoyados por las reconstrucciones filogenéticas para los marcadores fosfoenol piruvato carboxilasa (Fig. 3A) y tr$n A$-trnH (Fig. 3B), en los cuales la mayoría de individuos de $S$. purpurea forman un grupo monofilético y en los que algunas ramas terminales tienen agrupados individuos de S. mombim var. mombin y S. purpurea. Los resultados de ambos análisis sugieren: 1) un único origen para $S$. purpurea, 2) tiempo evolutivo corto para la divergencia de algunos linajes del género, 3) hibridación entre individuos de $S$. purpurea con $S$. mombin o $S$. radlkoferi en poblaciones locales. Ambas hipótesis deberán ser comprobadas o rechazadas ampliando el estudio con otros marcadores moleculares incluyendo más individuos de poblaciones en donde las especies crecen de manera simpátrica.

La unión del grupo en que se incluyen las especies de $S$. mombin-S. radlkoferi y el grupo en que están incluidas $S$. purpurea-S. mombin-S. radlkoferi requiere 58 pasos (Fig. 2); por lo anterior, sugerimos que el marcador trnS-trn $G$ es una región génica que nos permite diferen- ciar entre $S$. purpurea y sus dos especies hermanas. Cabe destacar que los haplotipos 14 (S. mombin-S. radlkoferi) y 2 ( $S$. purpurea) son los que unen a los grupos por lo que podría considerarse a este último haplotipo como el ancestral para S. purpurea (Fig. 2). Si este es el caso, la región en la que se distribuye el haplotipo 2 (poblaciones 45, 47 y 49) (Cuadro 2, Fig. 4) puede considerarse como el centro de origen de la especie. Estas poblaciones se encuentran en la provincia del Eje Neovolcánico, en el occidente de México entre los estados de Jalisco y Michoacán (Fig. 4), regiones en donde se propone que se han originado el maíz y frijol, entre otras especies cultivadas importantes (Piperno, 2011).

\section{Centros de domesticación}

De acuerdo con el análisis de contingencia anidada para Spondias purpurea, el grupo 1 contiene nueve haplotipos distribuidos en las poblaciones: 1, 12-13, 20- 21, 25, 27 $28,30,38-39,41-42,49$ y 53, ubicadas en la provincia de la Costa del Pacífico, en Centroamérica (Nicaragua), el Eje Neovolcánico (Michoacán y Jalisco), la Sierra Madre del Sur y la Depresión del Balsas (Morelos) (Figs. 1B, 5); $73 \%$ de los ejemplares provienen de poblaciones silvestres, $23 \%$ son de poblaciones con manejo agrícola y $4 \%$ con manejo silvícola (Fig. 1D). Este linaje es el que ha sido, en proporción, menos empleado por los grupos humanos. Las regiones en las que existen poblaciones silvestres y con manejo agrícola y/o silvícola dentro de este grupo son: Nicaragua, poblaciones 20 y 21, y en Michoacán, Jalisco y Nayarit, 41, 49 y 53, respectivamente. Estos datos sugieren dos centros de domesticación para los linajes dentro de este grupo, lo que coincide con los resultados de Miller y Schaal (2005).

El grupo 2 contiene 11 haplotipos distribuidos en las poblaciones $2,5,9,13-14,16,18-19,24,27-28,30$ $31,34-38,40,42,44,45-47,49-52$ y 54 de todas las provincias biogeográficas (Fig. 4); 69\% de los ejemplares provienen de poblaciones con manejo agrícola, $22 \%$ de poblaciones silvestres y $9 \%$ con manejo silvícola (Fig. 1D). Este linaje es el más extendido y es el que ha sido, en proporción, más empleado por los grupos humanos. 


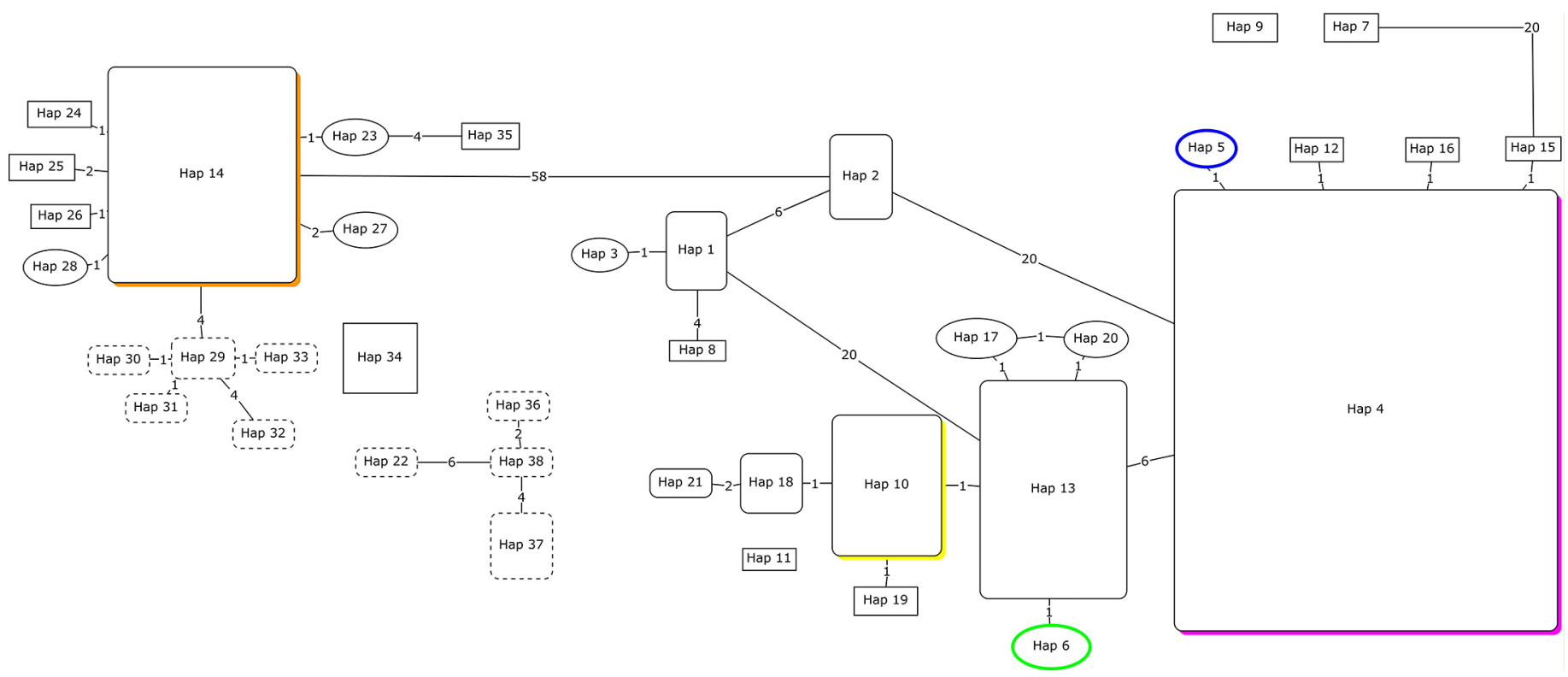

Figura 2: Red de haplotipos para cuatro especies de Spondias L. (S. mombin L. var. mombin, S. mombin L. var. globosa J.D. Mitch. \& D.C. Daly, S. radlkoferi Donn. Sm., S. testudinis J.D. Mitch. \& Daly, y S. purpurea L.). Los cuadros con bordes redondeados son haplotipos representados en poblaciones silvestres y con manejo agrícola; con bordes angulares corresponden a poblaciones con manejo silvícola y los óvalos a poblaciones silvestres.

Las regiones en las que existen poblaciones silvestres y con manejo agrícola y/o silvícola dentro de este grupo son: Costa Rica, poblaciones 9, 13 y 16; Honduras y Salvador, 24, 27 y 28; Guatemala, 30, 34 y 35; Jalisco, 4547; y Yucatán, 50 y 51. Cabe destacar que el haplotipo 4, que comparten los individuos con manejo agrícola y los de las poblaciones silvestres, es el más frecuente de entre los 20 haplotipos de $S$. purpurea (Cuadro 2). Por esa razón, no se puede discernir si el linaje se domesticó en alguna de estas regiones y posteriormente se dispersó a las diferentes regiones, o si en cada uno de estos sitios tendríamos un centro de domesticación independiente.

El grupo 3 contiene siete haplotipos distribuidos en las poblaciones 10, 21, 26, 29, 30, 42 y 48 de las Provincias Costa del Pacífico (Centroamérica desde Nicaragua hasta Guatemala), Depresión del Balsas (Morelos) y Península de Yucatán (Campeche) (Figs. 1C, 6); 80\% provienen de poblaciones con manejo agrícola y $20 \%$ de poblaciones silvestres (Fig. 1D). La región de Guatemala es la única en la que existen poblaciones silvestres y con manejo agrícola (29 y 30). Este resultado subraya nue- vamente la importancia de la región de Guatemala como centro de domesticación de la ciruela mexicana (Miller y Schaal, 2005).

El grupo 4 contiene un haplotipo de la población $5 \mathrm{y}$ el grupo 5, uno de la población 35 ambas de la Provincia de la Costa del Pacífico (Panamá y Guatemala, respectivamente); y ambos haplotipos con manejo agrícola (Figs. 1C, D, 7).

\section{Centros de diversidad genética}

En 12 de las 54 poblaciones se distribuyen solo especies de $S$. mombim var. mombin, S. mombim var. globosa y/o S. radlkoferi, por lo que éstas no fueron incluidas en el análisis de diversidad por poblaciones y los porcentajes de poblaciones con diferentes haplotipos hacen referencia solo a 44 poblaciones de $S$. purpurea (Cuadro 2). De estas 44 poblaciones, $69.05 \%$ presentan un haplotipo, $21.43 \%$ dos haplotipos, $4.76 \%$ tres haplotipos, $2.38 \%$ cuatro haplotipos y $2.38 \%$ cinco haplotipos de $S$. purpurea. Las poblaciones denominadas con los números 13 (Parque Nacional Palo Verde, Costa Rica), 30 (Amatitlán, Guatemala), 42 (Villa de Ayala, México) y 49 (Aguacate, Méxi- 


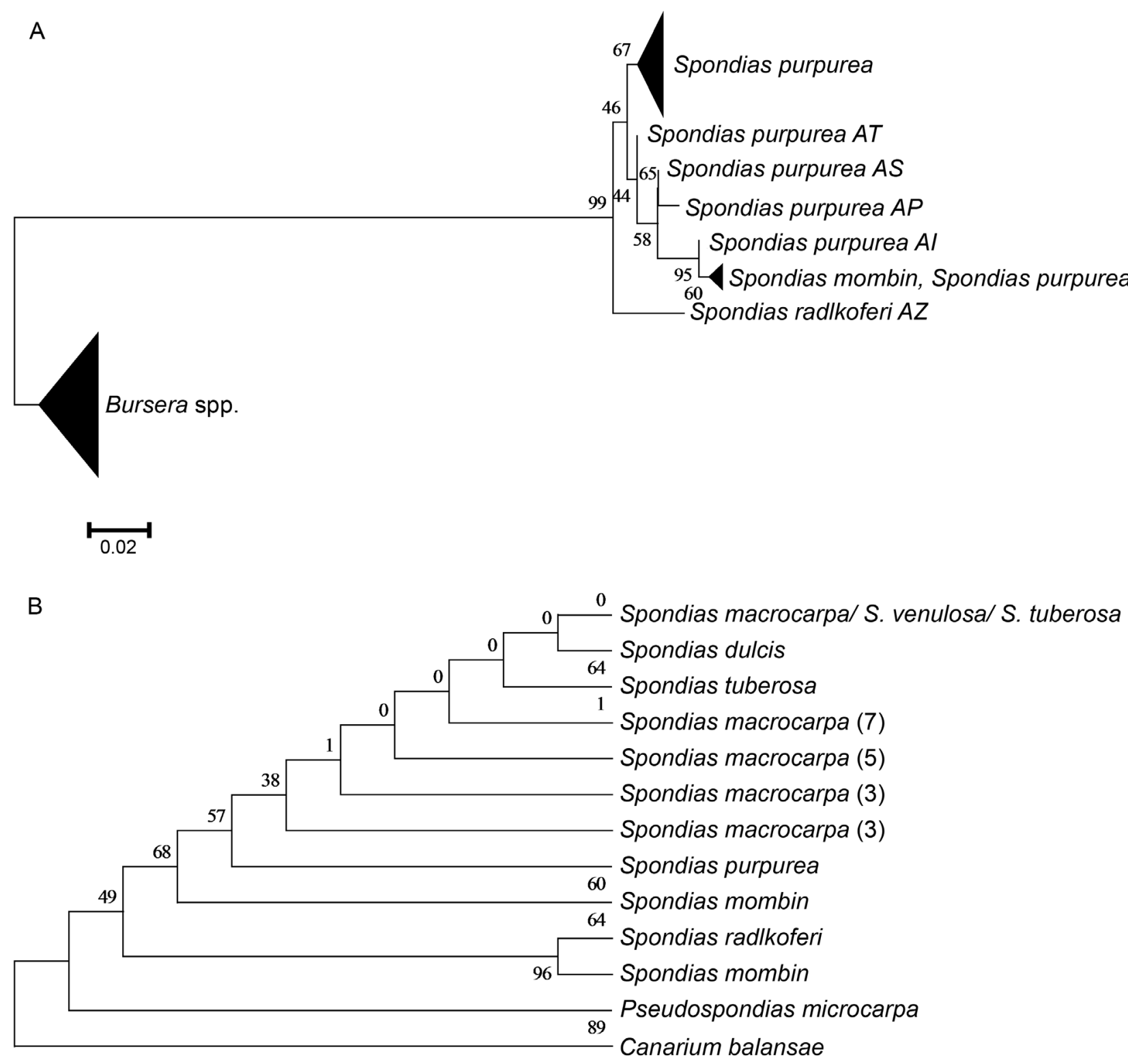

Figura 3: Reconstrucción filogenética (máxima verosimilitud) para: A. 99 secuencias del marcador de DNA nuclear fosfoenol piruvato carboxilasa para tres especies del género Spondias L. (Anacardiaceae; 51 secuencias, el par de letras finales en las ramas terminales que corresponden a S. purpurea son los haplotipos determinados por Miller (2008) y 19 especies de Bursera Jacq. ex L. (Burseraceae; 49 secuencias); B. región intergénica trnA-trnH de DNA de cloroplasto para siete especies del género Spondias L. (48 secuencias), Pseudospondias microcarpa (A. Rich.) Engl. (Anacardiaceae; 2 secuencias) y Canarium balansae Engl. (Burseraceae; 1 secuencia); Los valores para el bootstrap (1000 repeticiones) se presentan alrededor de los nodos.

co) son las que tienen tres o más haplotipos y en conjunto albergan ocho haplotipos únicos. Por lo tanto, deben ser consideradas en acciones de conservación como centros de diversidad genética de la ciruela mexicana.

Las poblaciones silvestres albergan la mayor diversidad genética, seguidas por las poblaciones con mane- jo agrícola y silvícola (Cuadro 3). En conjunto los datos indican que las poblaciones silvestres tienen todavía una mayor diversidad genética que las que tienen manejo agrícola. En este sentido, es importante conservar las poblaciones 13 (Parque Nacional Palo Verde, Costa Rica), 30 (Amatitlán, Guatemala), 39 (Parque Nacional Cañón Su- 


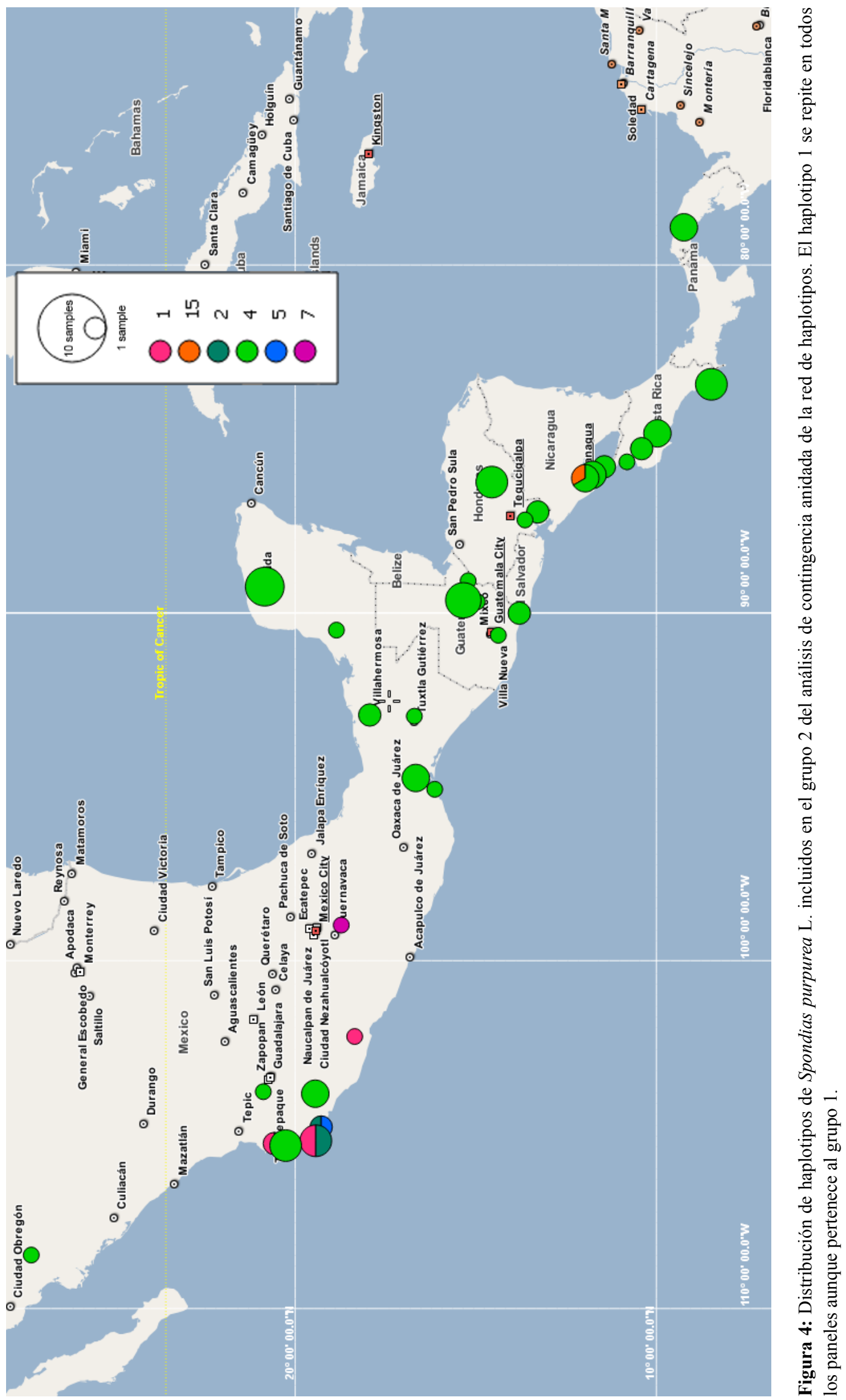




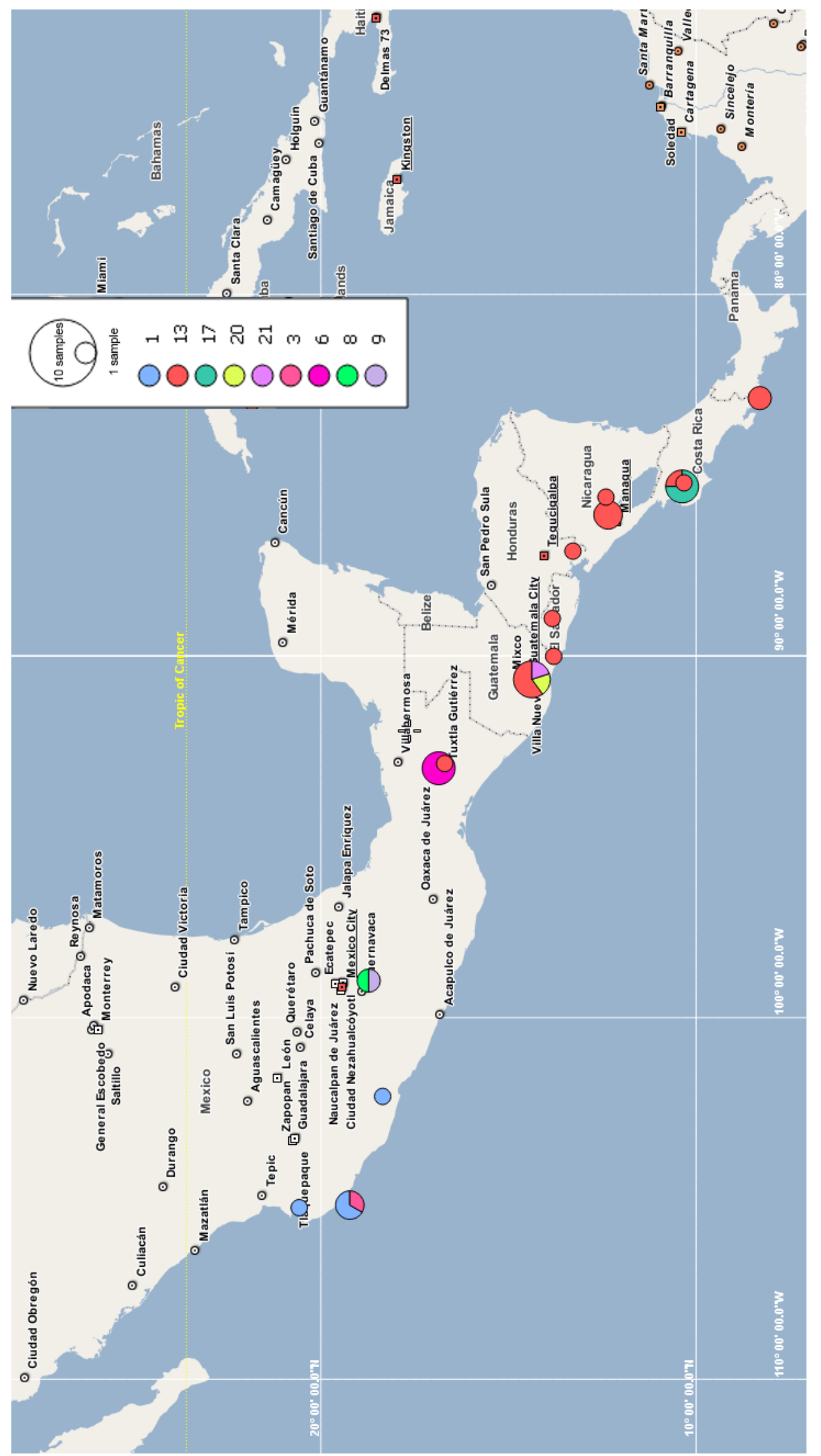

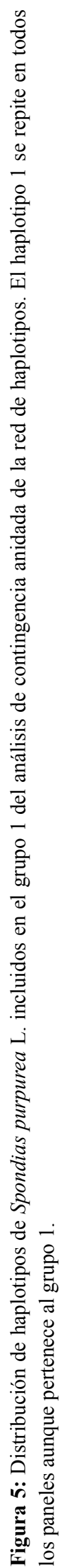




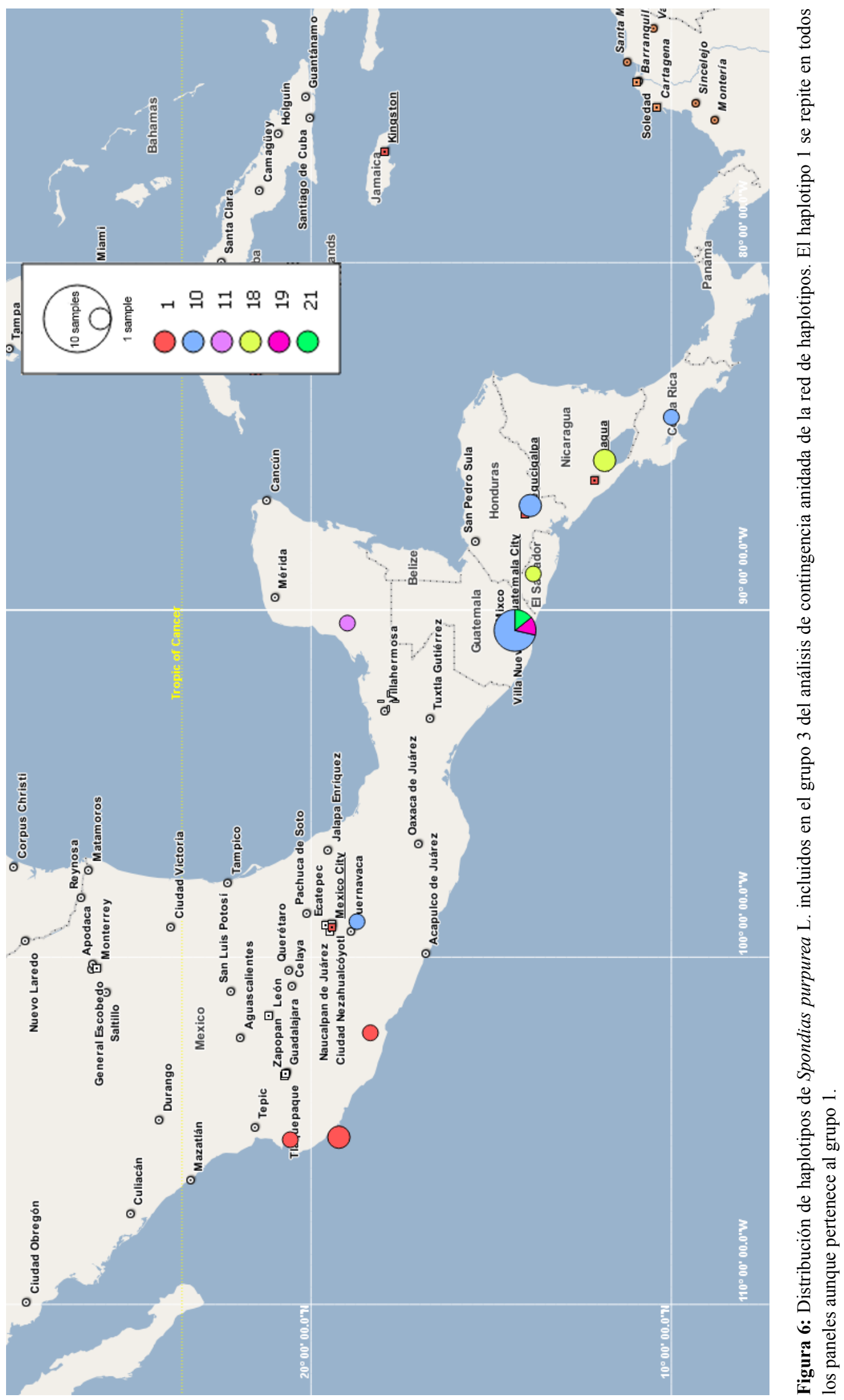



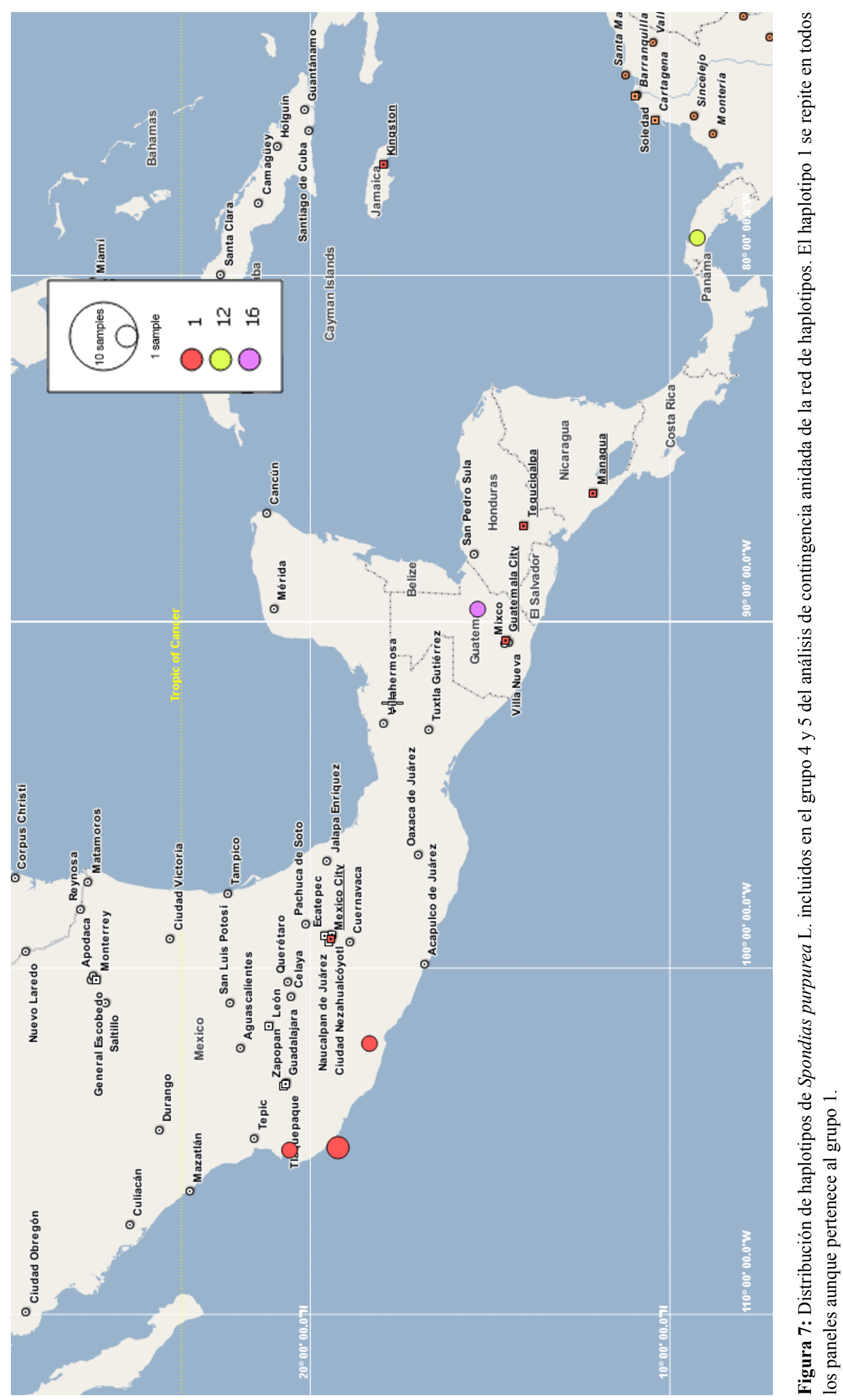
Cuadro 3: Número de secuencias (Secuencias) y de haplotipos (Hapl.) analizados; y diversidad haplotídica (Hd) y nucleotídica (p) de las provincias biogeográficas y clasificadas de acuerdo a su estatus de manejo en la población. $\mathrm{CP}=\mathrm{Costa}$ del Pacífico; EN=Eje Neovolcánico; $\mathrm{DB}=\mathrm{Depresión}$ del Balsas; SMS=Sierra Madre del Sur; GM=Golfo de México; LA=Los Altos de Chiapas; PY=Península de Yucatán. S=silvestre; MS=Manejo silvícola; MA=Manejo agrícola.

\begin{tabular}{lcccccccccc}
\hline & CP & EN & DB & SMS & GM & LA & PY & S & MS & MA \\
\hline Secuencias & 80 & 6 & 4 & 2 & 2 & 2 & 9 & 37 & 7 & 64 \\
Hapl. & 5 & 1 & 3 & 1 & 1 & 1 & 2 & 3 & 2 & 5 \\
Hd & 0.584 & --- & 0.833 & --- & --- & --- & 0.222 & 0.573 & 0.2857 & 0.471 \\
$\mathrm{p}$ & 0.002 & --- & 0.003 & --- & --- & --- & 0.001 & 0.001 & 0.0008 & 0.002 \\
\hline
\end{tabular}

midero, México), 47 (La Manzanilla, México), 49 (Aguacate, México) y 53 (Otates y Cantaranas, México) en las que se encuentran los siete haplotipos característicos de poblaciones silvestres $(2,3,6,17,20$ y 21) (Cuadros 1, 2).

Se encontró también que las poblaciones con manejo agrícola que presentan haplotipos que ya no se encuentran en poblaciones silvestres fueron la 42 (Villa de Ayala, México) en la provincia de la Depresión del Balsas y la 48 (Tinúm, México) en la Península de Yucatán. En relación con este hallazgo cabe destacar a la población 42 en la que se observaron cuatro haplotipos que pertenecen además a tres de los cinco grupos identificados en el análisis de contingencia anidada (Cuadro 1, Fig. 1B). Los resultados sugieren que para ambas poblaciones existen linajes únicos en las poblaciones con manejo agrícola que derivan de otros que ya no se encuentran en su forma silvestre o que no han sido registrados en nuestro esfuerzo de muestreo ni en el de Miller y Schaal (2005) y Miller (2008). La conservación de estos haplotipos podría enfocarse a constituir bancos de germoplasma que alberguen representantes de $S$. purpurea de las diferentes poblaciones con características morfológicas distintivas, así como incentivar y promover el manejo de la especie en los solares o huertos para conservar a la especie in circa situm.

La provincia biogeográfica con una mayor diversidad de haplotipos y nucleotídica fue la Depresión del Balsas, seguida de la Costa del Pacífico y la Península de Yucatán. Las menos diversas fueron el Eje Neovolcánico, la Sierra Madre del Sur, el Golfo de México y Los Altos de Chiapas. Estas últimas contienen un solo haplo- tipo (Cuadro 3). Aunque se espera que la estimación de la diversidad genética esté subestimada para las provincias biogeográficas por la falta de un muestreo sistemático en algunas de ellas, los estimadores que se obtuvieron en este trabajo nos sugieren que en varias provincias existe una mayor diversificación de esta especie que en otras.

Estos datos nos indican que la Depresión del Balsas debe considerarse como un sitio de diversidad genética de la ciruela donde enfocar los esfuerzos de mejoramiento de este árbol tropical como proponen Jamnadass et al. (2009); sin dejar a un lado los centros de diversidad genética del cultivo de la Costa del Pacífico (Jalisco-Nayarit y Michoacán) y el de la Península de Yucatán, con el objetivo de descentralizar los esfuerzos de conservación y mejoramiento genético que requieren los árboles tropicales (Jamnadass et al., 2009). Las estrategias de conservación in situ del germoplasma en los centros de domesticación pueden ser una táctica que permita un entendimiento del proceso de la domesticación y la diversificación de $S$. purpurea, así como un manejo integral de este recurso fitogenético. Se requiere realizar un muestreo más extenso, particularmente en las regiones aledañas a las poblaciones identificadas como centro de origen, domesticación y diversidad genética de la ciruela mexicana.

\section{CONCLUSIONES}

Los resultados de este estudio sugieren que en $S$. purpurea los linajes del grupo 2 y 3 son los que han sido introducidos con mayor frecuencia a los sistemas de cultivo, mientras 
que los del grupo 1 han sido moderadamente cultivados, con la mayor parte de sus representantes en las poblaciones silvestres, por lo que representan un recurso fitogenético importante. La presencia de estos haplotipos en que se encuentran tanto individuos silvestres, como con manejo silvícola y agrícola, sugieren varios eventos de domesticación de linajes particulares, todos ellos ocurridos en dos provincias biogeográficas: 1) Eje Neovolcánico, en su región occidente, y 2) Costa del Pacífico, en las intersecciones de Jalisco-Nayarit-Michoacán y de Guatemala-Nicaragua.

El análisis filogeográfico de las especies del género Spondias sugiere que la historia de domesticación de esta especie es compleja, con un centro de origen en la región occidental de la provincia del Eje Neovolcánico y centros de domesticación en la provincia de la Costa del Pacífico (Jalisco-Nayarit-Michoacán y Guatemala-Nicaragua). Los centros de diversidad genética de $S$. purpurea son además de los centros de domesticación, la Depresión del Balsas y la Península de Yucatán.

\section{CONTRIBUCIONES DE AUTORES}

MMF y NFF concibieron y diseñaron el estudio. NFF realizó los análisis de laboratorio. Todos los autores contribuyeron a la adquisición de datos y su interpretación. MMF y NFF escribieron el manuscrito con la ayuda de MRM. Todos los autores contribuyeron a la discusión, revisión y aprobación del manuscrito final.

\section{FINANCIAMIENTO}

Este estudio fue apoyado por el Servicio Nacional de Inspección y Certificación de Semillas-Sistema Nacional de Recursos Fitogenéticos para la Alimentación y Agricultura, FRU-CIR 11-2/12, proyecto: Diversidad genética de Spondias purpurea L., a MRM y MMF, y por el Consejo Nacional de Ciencia y Tecnología 306629 con una beca de maestría a NFF.

\section{AGRADECIMIENTOS}

A Marie-Stéphanie Samain y dos revisores anónimos por las sugerencias y comentarios que mejoraron la claridad y contenido del manuscrito. A Astrid Ramírez, Julia Ri- vero, Alfonso Castillo, Mónica Pech y Edgar Balam por la ayuda en el trabajo de laboratorio y campo. A Margarita Aguilar Espinosa por el apoyo en la cuantificación del DNA. A la colección viva de Spondias spp. del Centro Regional Universitario de la Península de Yucatán-Universidad Autónoma Chapingo.

\section{LITERATURA CITADA}

Andueza-Noh, R. H. 2012. Domesticación del acervo genético Mesoamericano del fríjol lima (Phaseolus lunatus L.). Tesis de doctorado. Centro de Investigación Científica de Yucatán, AC. Mérida, México. 117 pp.

Avise, J. C. 2000. Phylogeography: the history and formation of species. Harvard University Press. Cambridge, USA. 464 pp.

Boege, E. 2009. Centros de origen, pueblos indígenas y diversificación del maíz. Ciencias 92-93: 18-28.

Brody, J. R. y S. E. Kern. 2004. Sodium boric acid: a Tris-free, cooler conductive medium for DNA electrophoresis. BioTechniques 36(2): 214-216.

Burger, J. C., M. A. Chapman y J. M. Burke. 2008. Molecular insights into the evolution of crop plants. American Journal of Botany 95(2): 113-122. DOI: http://dx.doi. org/10.3732/ajb.95.2.113

Byrne, M. y M. Hankinson. 2012. Testing the variability of chloroplast sequences for plant phylogeography. Australian Journal of Botany 60(7): 569-574. DOI: http:// dx.doi.org/10.1071/BT12146

Casas, A., A. Otero-Arnaiz, E. Pérez-Negrón y A. ValienteBanuet. 2007. In situ management and domestication of plants in Mesoamerica. Annals of Botany 100(5): 11011115. DOI: http://dx.doi.org/10.1093/aob/mcm126

Clement, M., D. Posada y K. Crandall. 2000. TCS: a computer program to estimate gene genealogies. Molecular Ecology 9(10): 1657-1660. DOI: http://dx.doi.org/10.1046/j.1365294x.2000.01020.x

Croizat, L., G. Nelson y D. E. Rosen. 1974. Centers of origin and related concepts. Systematic Zoology 23(2): 265-287. DOI: http://dx.doi.org/10.2307/2412139

De Nova, J. A., R. Medina, J. C. Montero, A. Weeks, J. A. Rosell, M. E. Olson, L. E. Eguiarte y S. Magallón. 2012. Insights into the historical construction of species- 
rich Mesoamerican seasonally dry tropical forests: the diversification of Bursera (Burseraceae, Sapindales). New Phytologist 193(1): 276-287. DOI: http://dx.doi. org/10.1111/j.1469-8137.2011.03909.x

Doebley, J. F., B. S. Gaut y B. D. Smith. 2006. The molecular genetics of crop domestication. Cell 127(7): 1309-1321. DOI: http://dx.doi.org/10.1016/j.cell.2006.12.006

Engels, J. M. M., A. W. Ebert, I. Thormann y M. C. d. Vicente. 2006. Centres of crop diversity and/or origin, genetically modified crops and implications for plant genetic resources conservation. Genetic Resources and Crop Evolution 53(8): 1675-1688. DOI: http://dx.doi. org/10.1007/s10722-005-1215-y

Espinosa-Organista, D., S. O. Cruz y C. A. Zúñiga 2008. El conocimiento biogeográfico de las especies y su regionalización natural. In: Soberón, J., G. Halffter y J. Llorente-Bousquets (comps.). Capital natural de México, Vol 1: Conocimiento actual de la biodiversidad. Comisión Nacional para el Conocimiento y Uso de la Biodiversidad. México, D.F., México. Pp. 33-65.

Falcón, L. I. y A. Valera 2007. Extracción de ácidos nucleicos. In: Eguiarte, L. E., V. Souza y X. Aguirre (comps.). Ecología molecular. Instituto Nacional de Ecología, Secretaría de Medio Ambiente y Recursos Naturales. México, D.F., México. Pp. 499-516.

Genbank. 2015. National Center for Biotechnology Information http://www.ncbi.nlm.nih.gov/genbank/ (consultado enero de 2015).

Gross, B. L. y K. M. Olsen. 2010. Genetic perspectives on crop domestication. Trends in Plant Science 15(9): 529-537. DOI: http://dx.doi.org/10.1016/j.tplants.2010.05.008

Harlan, J. 1971. Agricultural origins: centers and non centers. Science 174(4008): 468-474.

Hernández-Verdugo, S., A. González-Rodríguez, P. Sánchez-Peña, A. Casas y K. Oyama. 2006. Estructura y diferenciación genética de poblaciones silvestres y domesticadas de chile del Noroeste de México analizada con isoenzimas y RAPDs. Revista Fitotecnia Mexicana 29(2): 25-29.

Hernández-Xolocotzi, E. 1998. Aspectos de la domesticación de plantas en México: una apreciación personal. In: Ramamoorthy, T. P., R. Bye, A. Lot y J. Fa (comps.).
Diversidad Biológica de México. Instituto de Biología, Universidad Autónoma de México. México, D.F., México. Pp. 715-735.

Jamnadass, R., A. Lowe e I. Dawson. 2009. Molecular markers and the management of tropical trees: the case of indigenous fruits. Tropical Plant Biology 2(1): 1-12. DOI: http://dx.doi.org/10.1007/s12042-008-9027-9

Kress, W. J., D. L. Erickson, F. A. Jones, N. G. Swenson, R. Perez, O. Sanjur y E. Bermingham. 2009. Plant DNA barcodes and a community phylogeny of a tropical forest dynamics plot in Panama. Proceedings of the National Academy of Sciences 106(44): 18621-18626. DOI: http:// dx.doi.org/10.1073/pnas.0909820106

Librado, P. y J. Rozas. 2009. DnaSP v5: a software for comprehensive analysis of DNA polymorphism data. Bioinformatics 25(11): 1451-1452.

Machado, M. C., P. C. L. d. Carvalho y C. v. d. Berg. 2015. Domestication, hybridization, speciation, and the origins of an economically important tree crop of Spondias (Anacardiaceae) from the Brazilian Caatinga dry forest. Neodiversity 8(1): 8-49. DOI: http://dx.doi.org/10.13102/neod.81.2

Miller, A. J. 2008. Characterization of a domesticated tree lineage (Spondias purpurea, Anacardiaceae) based on nuclear and chloroplast sequence data. Journal of the Torrey Botanical Society 135(4): 463-474.

Miller, A. J. y J. H. Knouft. 2006. GIS-based characterization of the geographic distributions of wild and cultivated populations of the mesoamerican fruit tree Spondias purpurea (Anacardiaceae). American Journal of Botany 93(12): 1757-1767. DOI: http://dx.doi.org/10.3732/ajb.93.12.1757

Miller, A. J. y B. A. Schaal. 2005. Domestication of a Mesoamerican cultivated fruit tree, Spondias purpurea. Proceedings of the National Academy of Sciences 102 (36): 12801-12806. DOI: http://dx.doi.org/10.1073/ pnas.0505447102

Miller, A. J. y B. A. Schaal. 2006. Domestication and the distribution of genetic variation in wild and cultivated populations of the Mesoamerican fruit tree Spondias purpurea L. (Anacardiaceae). Molecular Ecology 15(6): 1467-1480. DOI: http://dx.doi.org/10.1111/j.1365-294X. 2006.02834.x 
Nei, M. y S. Kumar 2000. Molecular Evolution and Phylogenetics. Oxford University Press, Inc. Oxford, UK. Pp. 250-259. Nybom, H., K. Weising y B. Rotter. 2014. DNA fingerprinting in botany: past, present, future. Investigative Genetics 5(1): 1-1. DOI: http://dx.doi.org/10.1186/2041-2223-5-1

Otero-Arnaiz, A., A. Casas, C. Bartolo, E. Pérez-Negrón y A. Valiente-Banuet. 2003. Evolution of Polaskia chichipe (Cactaceae) under domestication in the Tehuacán Valley, central Mexico: reproductive biology. American Journal of Botany 90(4): 593-602. DOI: http://dx.doi.org/10.3732/ajb.90.4.593

Parmentier, I., J. Duminil, M. Kuzmina, M. Philippe, D. W. Thomas, D. Kenfack, G. B. Chuyong, C. Cruaud y O. J. Hardy. 2013. How effective are DNA barcodes in the identification of African rainforest trees? PLOS ONE 8(4): e54921. DOI: http://dx.doi.org/10.1371/journal.pone.0054921

Parra, F., J. J. Blancas y A. Casas. 2012. Landscape management and domestication of Stenocereus pruinosus (Cactaceae) in the Tehuacán Valley: human guided selection and gene flow. Journal of Ethnobiology and Ethnomedicine 8: 32. DOI: http://dx.doi.org/10.1186/1746-4269-8-32

Perales-Rivera, H. R. y J. R. Aguirre-Rivera 2008. Biodiversidad humanizada. In: Soberón, J., G. Halffter y J. LlorenteBousquets (comps.). Capital natural de México, Vol. I: Conocimiento actual de la biodiversidad. Comisión Nacional para el Conocimiento y Uso de la Biodiversidad. México, D.F., México. Pp. 565-603.

Piperno, D. R. 2011. The origins of plant cultivation and domestication in the New World tropics. Patterns, process, and new developments. Current Anthropology 52(S4): S453-S470.

PopART. 2014. Population Analysis with Reticulate Trees v. 1.0. http://popart.otago.ac.nz.

Ruenes-Morales, M. de R., A. Casas, J. J. Jiménez-Osornio y J. Caballero. 2010. Etnobotánica de Spondias purpurea L. (Anacardiaceae) en la Península de Yucatán. Interciencia 35(4): 247-253.

Schaal, B. A., D. A. Hayworth, K. M. Olsen, J. T. Rauscher y W. A. Smith. 1998. Phylogeographic studies in plants: problems and prospects. Molecular Ecology 7(4): 465-474. DOI: http://dx.doi.org/10.1046/j.1365294x.1998.00318.x
Schaal, B. A. y K. M. Olsen. 2000. Gene genealogies and population variation in plants. Proceedings of the National Academy of Sciences 97(13): 7024-7029. DOI: http:// dx.doi.org/10.1073/pnas.97.13.7024

Shaw, J., E. B. Lickey, E. E. Schilling y R. L. Small. 2007. Comparison of whole chloroplast genome sequences to choose noncoding regions for phylogenetic studies in angiosperms: The tortoise and the hare III American Journal of Botany 94(3): 275-288. DOI: http://dx.doi. org/10.3732/ajb.94.3.275

Tamura, K., D. Peterson, N. Peterson, G. Stecher, M. Nei y S. Kumar. 2011. MEGA5: Molecular Evolutionary Genetics Analysis using Maximum Likelihood, Evolutionary Distance, and Maximum Parsimony Methods. Molecular Biology and Evolution 28(10): 2731-2739. DOI: http:// dx.doi.org/10.1093/molbev/msr121

Templeton, A. R. y C. F. Singt. 1993. A cladistic analysis of phenotypic associations with haplotypes inferred from restriction endonuclease mapping. IV. Nested analyses with cladogram uncertainty and recombination. Genetics 134(2): 659-669.

TROPICOS. 2015. Tropicos.org. Missouri Botanical Garden. http://www.tropicos.org (consultado enero de 2015).

Vavilov, N. I. 1951. Estudios sobre el origen de las plantas cultivadas. Traducción del trabajo aparecido en Bulletin of Applied Botany and Plant Breeding XVI (2), Leningrado, 1926. ACME Agency, Soc. de Resp. Ltda. Buenos Aires, Argentina. Pp. 1-126.

Weeks, A. 2009. Evolution of the pili nut genus (Canarium L., Burseraceae) and its cultivated species. Genetic Resources and Crop Evolution 56(6): 765-781. DOI: http://dx.doi. org/10.1007/s10722-008-9400-4

Weeks, A. y B. B. Simpson. 2004. Molecular genetic evidence for interspecific hybridization among endemic Hispaniolan Bursera (Burseraceae). American Journal of Botany 91(6): 976-984. DOI: http://dx.doi.org/10.3732/ ajb.91.6.976

Zeder, M. A., E. Emshwiller, B. D. Smith y D. G. Bradley. 2006. Documenting domestication: the intersection of genetics and archaeology. Trends in Genetics 22(3): 139155. DOI: http://dx.doi.org/10.1016/j.tig.2006.01.007 
Apéndice 1. Secuencias empleadas en el análisis de red de haplotipos por país (Centroamérica) o estado (México) y provincia biogeográfica en Mesoamérica. La latitud y longitud indican la localidad en que fueron colectadas y la población en que se agruparon, junto con su estatus en la población ( $\mathrm{S}=$ poblaciones silvestres, $\mathrm{MA}=$ manejo agrícola y $\mathrm{MS}=$ manejo silvícola). El número de accesión de Genbank e información del voucher (colector, número o clave de colecta, herbario o colección de referencia) del que se obtuvieron las secuencias del trabajo de Miller y Schaal (2005) (DQ163958-D164958), y en este trabajo (KY436830- KY436895) se presentan en las últimas dos columnas; mientras que en la de individuo/ espécimen se presenta el nombre de la secuencia registrada en Genbank. En UADY, colección de estacas Spondias, en CRUPY, colección de germoplasma de Spondias.

\begin{tabular}{|c|c|c|c|c|c|c|c|}
\hline Individuo/espécimen & País/Estado & Provincia Biogeográfica & Latitud & Longitud & Población & Accesión GB & Información del voucher \\
\hline 260c_hapZ & Panamá & Costa del Pacífico & $08^{\circ} 15^{\prime} 45.6^{\prime \prime} \mathrm{N}$ & $82^{\circ} 52^{\prime} 04.4 " \mathrm{O}$ & $1 \mathrm{MA}$ & DQ164032 & A. Miller 260c $(\mathrm{MO})$ \\
\hline 260d_hapZ & Panamá & Costa del Pacífico & $08^{\circ} 15^{\prime} 45.6^{\prime \prime} \mathrm{N}$ & $82^{\circ} 52^{\prime} 04.4^{\prime \prime O}$ & $1 \mathrm{MA}$ & DQ164033 & A. Miller $260 d(\mathrm{MO})$ \\
\hline 219e_hapAC & Costa Rica & Costa del Pacífico & $08^{\circ} 26^{\prime} 25.4^{\prime \prime} \mathrm{N}$ & $83^{\circ} 25^{\prime} 48.9^{\prime \prime} \mathrm{O}$ & $2 \mathrm{MA}$ & DQ164073 & A. Miller $219 e(\mathrm{MO})$ \\
\hline 219f_hapAC & Costa Rica & Costa del Pacífico & $08^{\circ} 26^{\prime} 25.4^{\prime \prime} \mathrm{N}$ & $83^{\circ} 25^{\prime} 48.9^{\prime \prime O}$ & $2 \mathrm{MA}$ & DQ164074 & A. Miller $219 f(\mathrm{MO})$ \\
\hline 219g_hapAC & Costa Rica & Costa del Pacífico & $08^{\circ} 26^{\prime} 25.4^{\prime \prime} \mathrm{N}$ & $83^{\circ} 25^{\prime} 48.9^{\prime \prime} \mathrm{O}$ & $2 \mathrm{MA}$ & DQ164075 & A. Miller $219 \mathrm{~g}(\mathrm{MO})$ \\
\hline 219h_hapAC & Costa Rica & Costa del Pacífico & $08^{\circ} 26^{\prime} 25.4^{\prime \prime} \mathrm{N}$ & $83^{\circ} 25^{\prime} 48.9^{\prime \prime} \mathrm{O}$ & $2 \mathrm{MA}$ & DQ164076 & A. Miller $219 h(\mathrm{MO})$ \\
\hline 216b_G & Costa Rica & Costa del Pacífico & $08^{\circ} 26^{\prime} 24^{\prime \prime} \mathrm{N}$ & $83^{\circ} 33^{\prime} 36^{\prime \prime O}$ & $3 \mathrm{MS}$ & DQ163963 & A. Miller $216 b(\mathrm{MO})$ \\
\hline 216c_hapG & Costa Rica & Costa del Pacífico & $08^{\circ} 26^{\prime} 24^{\prime \prime} \mathrm{N}$ & $83^{\circ} 33^{\prime} 36^{\prime \prime O}$ & $3 \mathrm{MS}$ & DQ163964 & A. Miller $216 c(\mathrm{MO})$ \\
\hline 216e_G & Costa Rica & Costa del Pacífico & $08^{\circ} 26^{\prime} 24^{\prime \prime} \mathrm{N}$ & $83^{\circ} 33^{\prime} 36^{\prime \prime O}$ & $3 \mathrm{MS}$ & DQ163965 & A. Miller $216 e(\mathrm{MO})$ \\
\hline 240_hapG & Panamá & Costa del Pacífico & $08^{\circ} 33^{\prime} 41^{\prime \prime} \mathrm{N}$ & $79^{\circ} 57^{\prime} 02^{\prime \prime O}$ & $4 \mathrm{~S}$ & DQ163981 & A. Miller $240(\mathrm{MO})$ \\
\hline 228a_hapI & Panamá & Costa del Pacífico & $09^{\circ} 09^{\prime} 52^{\prime \prime} \mathrm{N}$ & $79^{\circ} 49^{\prime} 17^{\prime \prime O}$ & $6 \mathrm{~S}$ & DQ163971 & A. Miller $228 a(\mathrm{MO})$ \\
\hline 228h_2_hapG & Panamá & Costa del Pacífico & $09^{\circ} 09^{\prime} 52^{\prime \prime} \mathrm{N}$ & $79^{\circ} 49^{\prime} 17^{\prime \prime} \mathrm{O}$ & $6 \mathrm{~S}$ & DQ163972 & A. Miller $228 \mathrm{~h}(\mathrm{MO})$ \\
\hline 228i_1_hapJ & Panamá & Costa del Pacífico & $09^{\circ} 09^{\prime} 52^{\prime \prime} \mathrm{N}$ & $79^{\circ} 49^{\prime} 17^{\prime \prime} \mathrm{O}$ & $6 \mathrm{~S}$ & DQ163973 & A. Miller $228 i(\mathrm{MO})$ \\
\hline 228b_hapG & Panamá & Costa del Pacífico & $09^{\circ} 09^{\prime} 52^{\prime \prime} \mathrm{N}$ & $79^{\circ} 49^{\prime} 17^{\prime \prime O}$ & $6 \mathrm{~S}$ & DQ163974 & A. Miller $228 b(\mathrm{MO})$ \\
\hline 235e_hapK & Panamá & Costa del Pacífico & $09^{\circ} 10^{\prime} 31^{\prime \prime} \mathrm{N}$ & $78^{\circ} 47^{\prime} 011^{\prime \prime O}$ & $7 \mathrm{~S}$ & DQ163980 & A. Miller $235 e(\mathrm{MO})$ \\
\hline 227a_hapU & Panamá & Costa del Pacífico & $09^{\circ} 10^{\prime} \mathrm{N}$ & $79^{\circ} 50^{\prime} \mathrm{O}$ & $7 \mathrm{~S}$ & DQ164002 & A. Miller $227 a(\mathrm{MO})$ \\
\hline 227c_hapU & Panamá & Costa del Pacífico & $09^{\circ} 10^{\prime} \mathrm{N}$ & $79^{\circ} 50^{\prime} \mathrm{O}$ & $7 \mathrm{~S}$ & DQ164003 & A. Miller $227 c(\mathrm{MO})$ \\
\hline 227b_hapU & Panamá & Costa del Pacífico & $09^{\circ} 10^{\prime} \mathrm{N}$ & $79^{\circ} 50^{\prime} \mathrm{O}$ & $7 \mathrm{~S}$ & DQ164004 & A. Miller $227 b(\mathrm{MO})$ \\
\hline 236a_hapAC & Panamá & Costa del Pacífico & $09^{\circ} 13^{\prime} 13.2^{\prime \prime} \mathrm{N}$ & $78^{\circ} 55^{\prime} 03.6^{\prime \prime O}$ & $5 \mathrm{MA}$ & DQ164077 & A. Miller $236 a(\mathrm{MO})$ \\
\hline 236c_hapAC & Panamá & Costa del Pacífico & $09^{\circ} 13^{\prime} 13.2^{\prime \prime} \mathrm{N}$ & $78^{\circ} 55^{\prime} 03.6^{\prime \prime} \mathrm{O}$ & $5 \mathrm{MA}$ & DQ164078 & A. Miller $236 c(\mathrm{MO})$ \\
\hline 236e_hapAC & Panamá & Costa del Pacífico & $09^{\circ} 13^{\prime} 13.2^{\prime \prime} \mathrm{N}$ & $78^{\circ} 55^{\prime} 03.6^{\prime \prime O}$ & $5 \mathrm{MA}$ & DQ164079 & A. Miller 236e $(\mathrm{MO})$ \\
\hline 236f_hapAC & Panamá & Costa del Pacífico & $09^{\circ} 13^{\prime} 13.2^{\prime \prime} \mathrm{N}$ & $78^{\circ} 55^{\prime} 03.6 " \mathrm{O}$ & $5 \mathrm{MA}$ & DQ164080 & A. Miller $236 f(\mathrm{MO})$ \\
\hline 231a_1_hapG & Panamá & Costa del Pacífico & $09^{\circ} 14^{\prime} 56^{\prime \prime} \mathrm{N}$ & $78^{\circ} 57^{\prime} 02^{\prime \prime} \mathrm{O}$ & $8 \mathrm{MS}$ & DQ163975 & A. Miller $231 a(\mathrm{MO})$ \\
\hline 231b_1_hapG & Panamá & Costa del Pacífico & $09^{\circ} 14^{\prime} 56^{\prime \prime} \mathrm{N}$ & $78^{\circ} 57^{\prime} 02^{\prime \prime O}$ & $8 \mathrm{MS}$ & DQ163976 & A. Miller $231 b(\mathrm{MO})$ \\
\hline 231c_1_hapG & Panamá & Costa del Pacífico & $09^{\circ} 14^{\prime} 56^{\prime \prime} \mathrm{N}$ & $78^{\circ} 57^{\prime} 02^{\prime \prime O}$ & $8 \mathrm{MS}$ & DQ163977 & A. Miller 231c (MO) \\
\hline 231d_1_hapG & Panamá & Costa del Pacífico & $09^{\circ} 14^{\prime} 56^{\prime \prime} \mathrm{N}$ & $78^{\circ} 57^{\prime} 02^{\prime \prime O}$ & $8 \mathrm{MS}$ & DQ163978 & A. Miller 231d (MO) \\
\hline 231e_1_hapG & Panamá & Costa del Pacífico & $09^{\circ} 14^{\prime} 56^{\prime \prime} \mathrm{N}$ & $78^{\circ} 57^{\prime} 02^{\prime \prime O}$ & $8 \mathrm{MS}$ & DQ163979 & A. Miller 231e $(\mathrm{MO})$ \\
\hline 201b_hapAC & Costa Rica & Costa del Pacífico & $09^{\circ} 58^{\prime} 12^{\prime \prime} \mathrm{N}$ & $84^{\circ} 50^{\prime} 24^{\prime \prime} \mathrm{O}$ & $9 \mathrm{MA}$ & DQ164070 & A. Miller $201 b(\mathrm{MO})$ \\
\hline 201d_hapAC & Costa Rica & Costa del Pacífico & $09^{\circ} 58^{\prime} 12^{\prime \prime} \mathrm{N}$ & $84^{\circ} 50^{\prime} 24^{\prime \prime O}$ & $9 \mathrm{MA}$ & DQ164071 & A. Miller 201d (MO) \\
\hline 201f_hapAC & Costa Rica & Costa del Pacífico & $09^{\circ} 58^{\prime} 12^{\prime \prime} \mathrm{N}$ & $84^{\circ} 50^{\prime} 24^{\prime \prime O}$ & $9 \mathrm{MA}$ & DQ164072 & A. Miller $201 f(\mathrm{MO})$ \\
\hline 79 hapS & Costa Rica & Costa del Pacífico & $10^{\circ} 00^{\prime} \mathrm{N}$ & $84^{\circ} 27^{\prime} \mathrm{O}$ & $10 \mathrm{MS}$ & DQ164001 & A. Miller $79(\mathrm{MO})$ \\
\hline
\end{tabular}


Apéndice 1. Continuación.

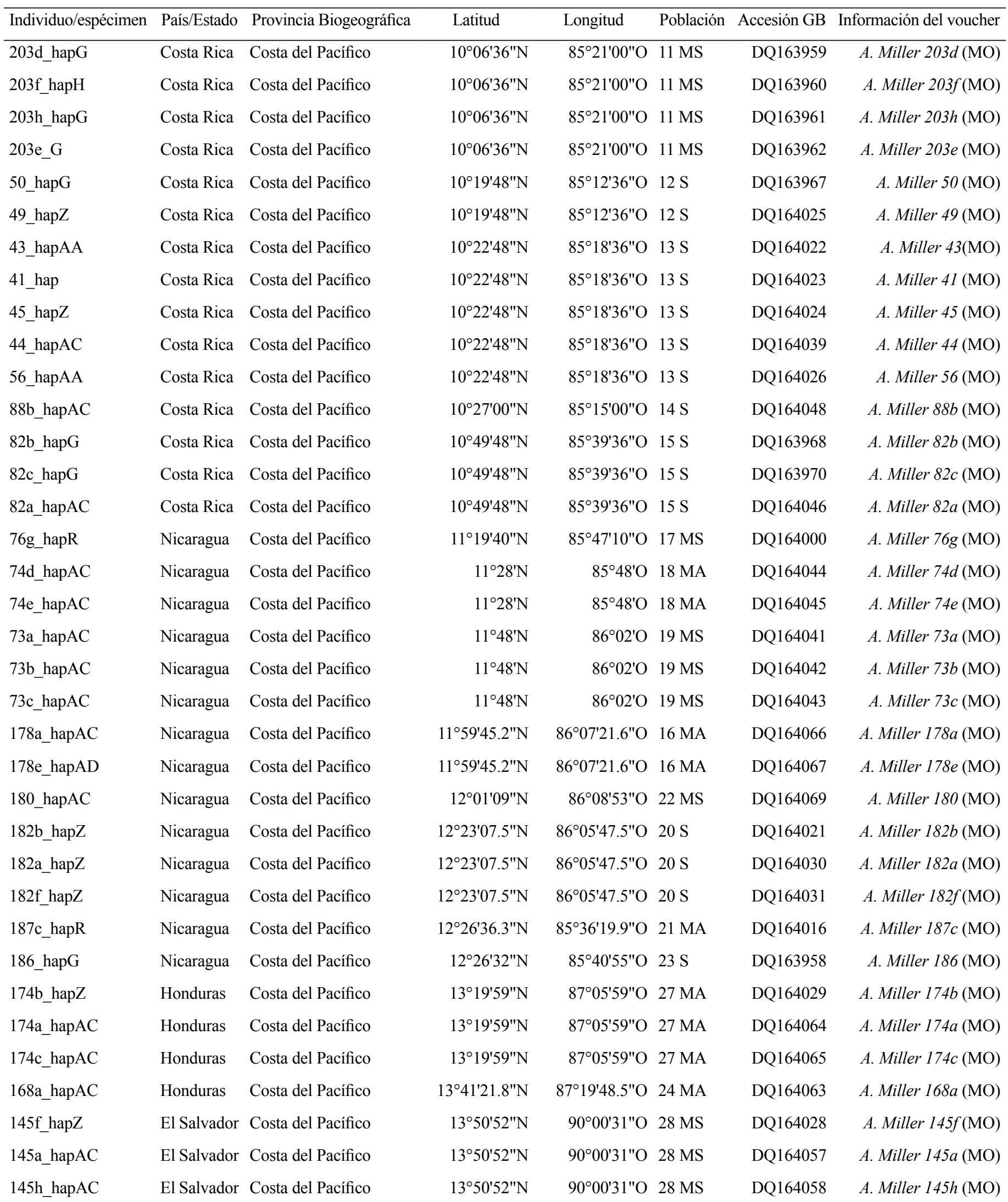


Apéndice 1. Continuación.

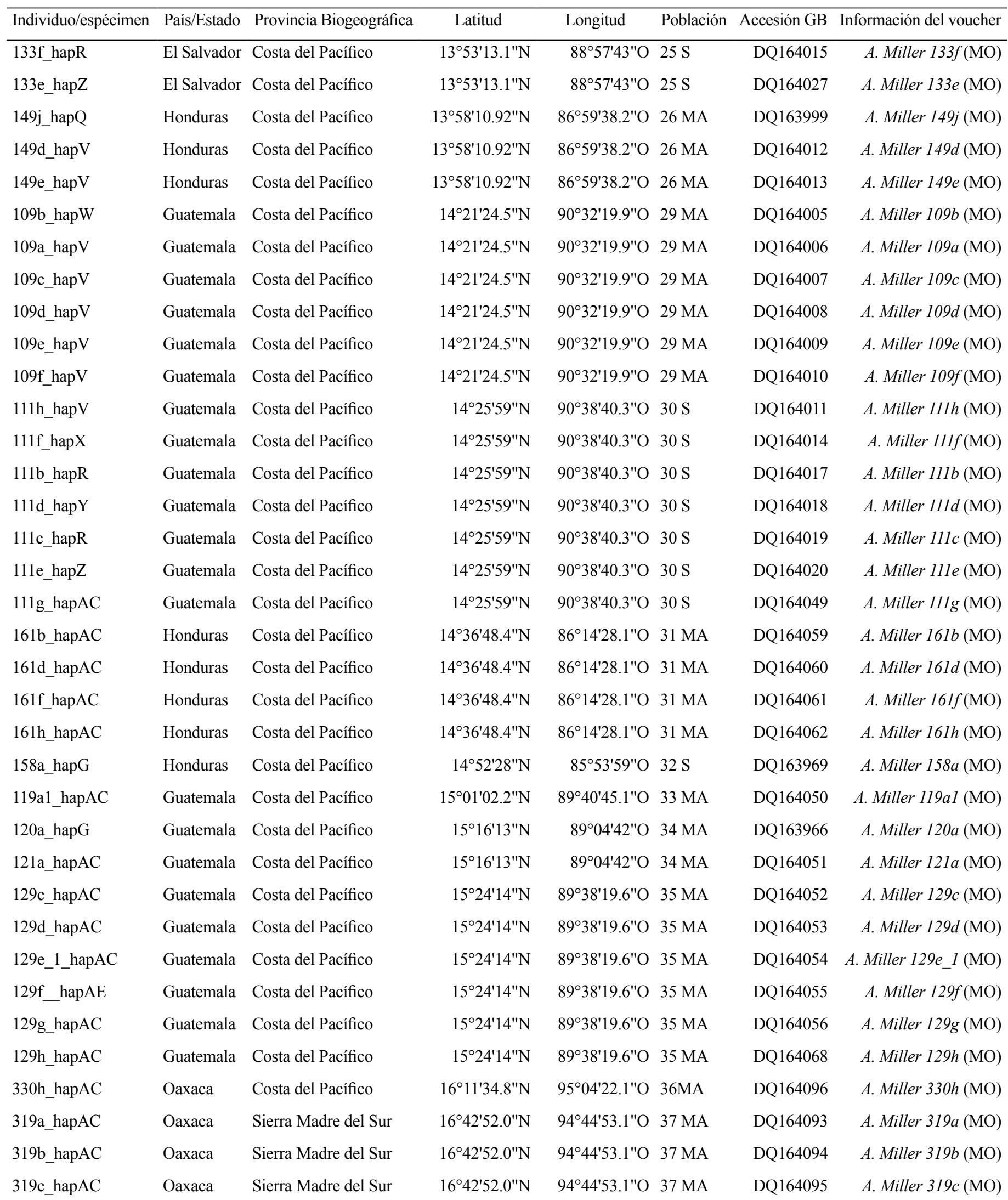


Apéndice 1. Continuación.

\begin{tabular}{|c|c|c|c|c|c|c|c|}
\hline Individuo/espécimen & País/Estado & Provincia Biogeográfica & Latitud & Longitud & Población & Accesión GB & Información del voucher \\
\hline 321_hapG & Oaxaca & Sierra Madre del Sur & $16^{\circ} 42^{\prime} 52^{\prime \prime} \mathrm{N}$ & $94^{\circ} 44^{\prime} 53^{\prime \prime O}$ & $37 \mathrm{~S}$ & DQ163983 & A. Miller $321(\mathrm{MO})$ \\
\hline 326g_hapZ & Chiapas & Los Altos de Chiapas & $16^{\circ} 45^{\prime} 16.4^{\prime \prime} \mathrm{N}$ & $92^{\circ} 58^{\prime} 18.3^{\prime \prime} \mathrm{O}$ & $38 \mathrm{~S}$ & DQ164037 & A. Miller $326 g(\mathrm{MO})$ \\
\hline 326a_hapAC & Chiapas & Los Altos de Chiapas & $16^{\circ} 45^{\prime} 16.4^{\prime \prime} \mathrm{N}$ & $92^{\circ} 58^{\prime} 18.3^{\prime \prime} \mathrm{O}$ & $38 \mathrm{~S}$ & DQ164081 & A. Miller $326 a(\mathrm{MO})$ \\
\hline 325c_hapAB & Chiapas & Los Altos de Chiapas & $16^{\circ} 54^{\prime} 47.2^{\prime \prime} \mathrm{N}$ & $93^{\circ} 06^{\prime} 10.6^{\prime \prime O}$ & $39 \mathrm{~S}$ & DQ164035 & A. Miller $325 c(\mathrm{MO})$ \\
\hline 325b_hapAB & Chiapas & Los Altos de Chiapas & $16^{\circ} 54^{\prime} 47.2^{\prime \prime} \mathrm{N}$ & $93^{\circ} 06^{\prime} 10.6^{\prime \prime O}$ & $39 \mathrm{~S}$ & DQ164034 & A. Miller $325 b(\mathrm{MO})$ \\
\hline 325d_hapAB & Chiapas & Los Altos de Chiapas & $16^{\circ} 54^{\prime} 47.2^{\prime \prime} \mathrm{N}$ & $93^{\circ} 06^{\prime} 10.6^{\prime \prime O}$ & $39 \mathrm{~S}$ & DQ164036 & A. Miller $325 d(\mathrm{MO})$ \\
\hline Tabasco Poblana & Tabasco & Golfo de México & $17^{\circ} 58^{\prime} 34.67^{\prime \prime} \mathrm{N}$ & $92^{\circ} 56^{\prime} 9.52^{\prime \prime} \mathrm{O}$ & $40 \mathrm{MA}$ & KY436863 & N. Fortuny, Villa \\
\hline Tabasco Criolla & Tabasco & Golfo de México & $17^{\circ} 58^{\prime} 34.67^{\prime \prime} \mathrm{N}$ & $92^{\circ} 56^{\prime} 9.52^{\prime \prime O}$ & $40 \mathrm{MA}$ & KY436864 & $\begin{array}{r}\text { Hermosa 1, UADY } \\
N . \text { Fortuny, Villa } \\
\text { Hermosa 2, UADY }\end{array}$ \\
\hline 303A_hapO & Michoacán & Eje Neovolcánico & $18^{\circ} 23^{\prime} 15.7^{\prime \prime N}$ & $102^{\circ} 10^{\prime} 44.9^{\prime \prime O}$ & $41 \mathrm{~S}$ & DQ163993 & A. Miller $303 \mathrm{~A}(\mathrm{MO})$ \\
\hline Mansa Mich 1 & Michoacán & Eje Neovolcánico & $18^{\circ} 23^{\prime} 15.7^{\prime \prime} \mathrm{N}$ & $102^{\circ} 10^{\prime} 44.9^{\prime \prime O}$ & $41 \mathrm{~S}$ & KY436843 & Mich 1, CRUPY \\
\hline 311_hapG & Veracruz & Golfo de México & $18^{\circ} 37^{\prime} 12^{\prime \prime N}$ & $96^{\circ} 24^{\prime} 36^{\prime \prime O}$ & $43 \mathrm{~S}$ & DQ163982 & A. Miller $311(\mathrm{MO})$ \\
\hline Tepal Mor & Morelos & Depresión del Balsas & $18^{\circ} 38^{\prime} 51.24^{\prime \prime} \mathrm{N}$ & $98^{\circ} 57^{\prime} 38.85^{\prime \prime O}$ & $42 \mathrm{MA}$ & KY436855 & Tepalcingo 1, CRUPY \\
\hline Huautleca Mor & Morelos & Depresión del Balsas & $18^{\circ} 38^{\prime} 51.24^{\prime \prime} \mathrm{N}$ & $98^{\circ} 57^{\prime} 38.85^{\prime \prime O}$ & $42 \mathrm{MA}$ & KY436856 & Tepalcingo 2, CRUPY \\
\hline Ticumán Mor & Morelos & Depresión del Balsas & $18^{\circ} 38^{\prime} 51.24^{\prime \prime} \mathrm{N}$ & $98^{\circ} 57^{\prime} 38.85^{\prime \prime O}$ & $42 \mathrm{MA}$ & KY436857 & Tepalcingo 3, CRUPY \\
\hline Colorada Mor & Morelos & Depresión del Balsas & $18^{\circ} 38^{\prime} 51.24^{\prime \prime} \mathrm{N}$ & $98^{\circ} 57^{\prime} 38.85^{\prime \prime O}$ & $42 \mathrm{MA}$ & KY436858 & Tepalcingo 5, CRUPY \\
\hline $\begin{array}{l}\text { Cuernavaca Hoil } 4 \\
\text { Mor }\end{array}$ & Morelos & Depresión del Balsas & $18^{\circ} 38^{\prime} 51.24^{\prime \prime} \mathrm{N}$ & $98^{\circ} 57^{\prime} 38.85^{\prime \prime O}$ & $42 \mathrm{MA}$ & KY436859 & Tepalcingo 4, CRUPY \\
\hline $\begin{array}{l}\text { Cuernavaca agria } \\
\text { Mor }\end{array}$ & Morelos & Depresión del Balsas & $18^{\circ} 45^{\prime} 10.42^{\prime \prime N}$ & $98^{\circ} 58^{\prime} 36.1 " \mathrm{O}$ & $42 \mathrm{MA}$ & KY436853 & $\begin{array}{r}\text { Cuernavaca Hoil } 4 \text { Mor, } \\
\text { CRUPY }\end{array}$ \\
\hline Macho Mor & Morelos & Depresión del Balsas & $18^{\circ} 45^{\prime} 10.42^{\prime \prime N}$ & $98^{\circ} 58^{\prime} 36.1 " \mathrm{O}$ & $42 \mathrm{MA}$ & KY436854 & $\begin{array}{r}\text { Tepalcingo macho, } \\
\text { CRUPY }\end{array}$ \\
\hline Morelos Cerro 1 & Morelos & Depresión del Balsas & $18^{\circ} 45^{\prime} 8.34^{\prime \prime} \mathrm{N}$ & $98^{\circ} 58^{\prime} 47.34 " \mathrm{O}$ & $42 \mathrm{MA}$ & KY436844 & M. Ferrer, San Antonio \\
\hline Morelos Cerro 2 & Morelos & Depresión del Balsas & $18^{\circ} 45^{\prime} 8.34^{\prime \prime} \mathrm{N}$ & $98^{\circ} 58^{\prime} 47.34^{\prime \prime O}$ & $42 \mathrm{MA}$ & KY436845 & $\begin{array}{r}1, \mathrm{UADY} \\
\text { M. Ferrer, San Antonio }\end{array}$ \\
\hline Morelos Cerro 3 & Morelos & Depresión del Balsas & $18^{\circ} 45^{\prime} 8.34^{\prime \prime} \mathrm{N}$ & $98^{\circ} 58^{\prime} 47.34^{\prime \prime O}$ & $42 \mathrm{MA}$ & KY436846 & $\begin{array}{r}2, \mathrm{UADY} \\
\text { M. Ferrer, San Antonio }\end{array}$ \\
\hline Morelos Cerro 4 & Morelos & Depresión del Balsas & $18^{\circ} 45^{\prime} 8.34^{\prime \prime} \mathrm{N}$ & $98^{\circ} 58^{\prime} 47.34^{\prime \prime O}$ & $42 \mathrm{MA}$ & KY436847 & $\begin{array}{r}\text { 3, UADY } \\
\text { M. Ferrer, San Antonio } \\
4, \mathrm{UADY}\end{array}$ \\
\hline Morelos Amarilla & Morelos & Depresión del Balsas & $18^{\circ} 45^{\prime} 8.34^{\prime \prime} \mathrm{N}$ & $98^{\circ} 58^{\prime} 47.34^{\prime \prime O}$ & $42 \mathrm{MA}$ & KY436848 & $\begin{array}{r}\text { M. Ferrer, San Antonio } \\
5, \mathrm{UADY}\end{array}$ \\
\hline Morelos Temporal & Morelos & Depresión del Balsas & $18^{\circ} 45^{\prime} 8.34^{\prime \prime} \mathrm{N}$ & $98^{\circ} 58^{\prime} 47.34^{\prime \prime} \mathrm{O}$ & $42 \mathrm{MA}$ & KY436849 & M. Ferrer, San Antonio \\
\hline Morelos Roja 1 & Morelos & Depresión del Balsas & $18^{\circ} 45^{\prime} 8.34^{\prime \prime} \mathrm{N}$ & $98^{\circ} 58^{\prime} 47.34 " \mathrm{O}$ & $42 \mathrm{MA}$ & KY436850 & M. Ferrer, San Antonio \\
\hline Morelos Roja 2 & Morelos & Depresión del Balsas & $18^{\circ} 45^{\prime} 8.34^{\prime \prime} \mathrm{N}$ & $98^{\circ} 58^{\prime} 47.34^{\prime \prime O}$ & $43 \mathrm{MA}$ & KY436851 & $\begin{array}{r}\text { 7, UADY } \\
\text { M. Ferrer, San Antonio } \\
\text { 8, UADY }\end{array}$ \\
\hline Morelos & Morelos & Depresión del Balsas & $18^{\circ} 45^{\prime} 8.34 " \mathrm{~N}$ & $98^{\circ} 58^{\prime} 47.34^{\prime \prime O}$ & $42 \mathrm{MA}$ & KY436852 & M. Ferrer, San Antonio \\
\hline $\begin{array}{l}\text { Cuernavaqueña } \\
\text { Campeche Campech } \\
\text { abal } 4\end{array}$ & Campeche & Península de Yucatán & $18^{\circ} 53^{\prime} 61 " \mathrm{~N}$ & $89^{\circ} 89^{\prime} 47^{\prime \prime O}$ & $44 \mathrm{MA}$ & KY436830 & $\begin{array}{r}\text { 9, UADY } \\
\text { R. Ruenes, Calakmul 1, } \\
\text { UADY }\end{array}$ \\
\hline
\end{tabular}


Apéndice 1. Continuación.

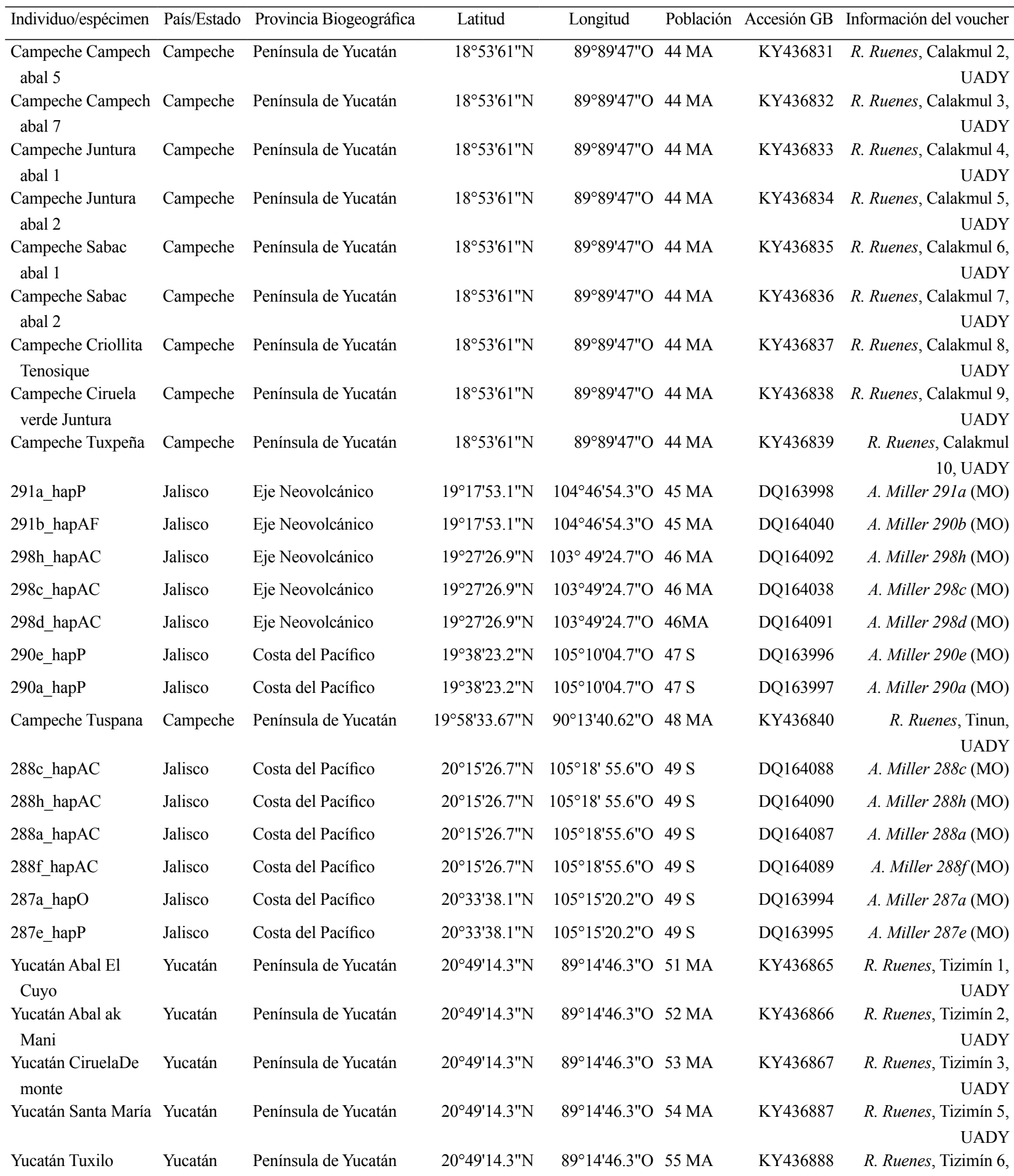


Apéndice 1. Continuación.

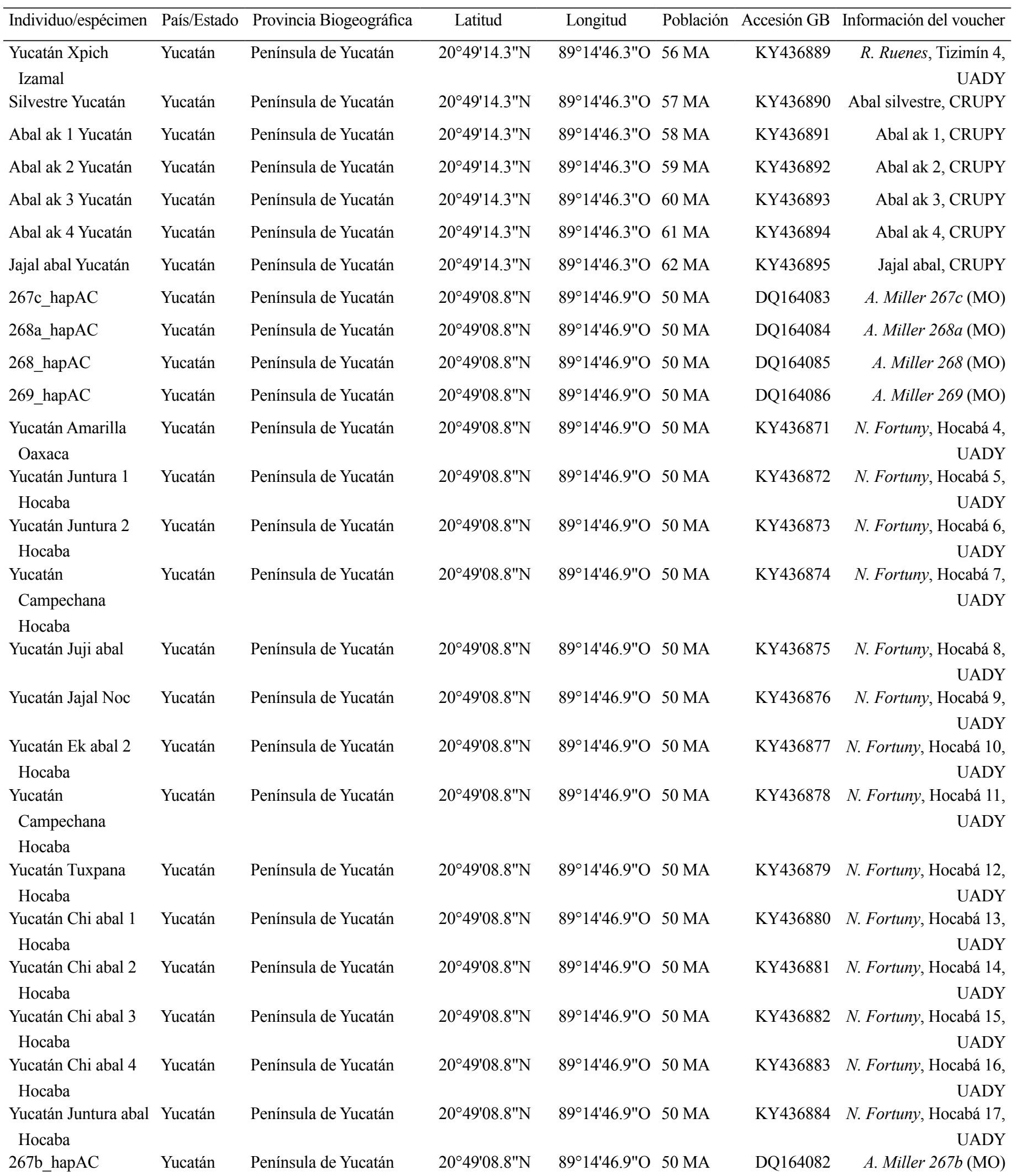


Apéndice 1. Continuación.

\begin{tabular}{|c|c|c|c|c|c|c|c|}
\hline Individuo/espécimen & País/Estado & Provincia Biogeográfica & Latitud & Longitud & Población & Accesión GB & Información del voucher \\
\hline $\begin{array}{l}\text { Yucatán Ek abal } 1 \\
\text { Hocaba }\end{array}$ & Yucatán & Península de Yucatán & $20^{\circ} 49^{\prime} 08.8^{\prime \prime} \mathrm{N}$ & $89^{\circ} 14^{\prime} 46.9^{\prime \prime O}$ & $50 \mathrm{MA}$ & KY436868 & $\begin{array}{r}\text { N. Fortuny Hocabá } 1, \\
\text { UADY }\end{array}$ \\
\hline $\begin{array}{l}\text { Yucatán Huhi abal } \\
\text { Hocaba }\end{array}$ & Yucatán & Península de Yucatán & $20^{\circ} 49^{\prime} 08.8^{\prime \prime} \mathrm{N}$ & $89^{\circ} 14 ' 46.9^{\prime \prime} \mathrm{O}$ & $50 \mathrm{MA}$ & KY436869 & $\begin{array}{r}\text { N. Fortuny, Hocabá 2, } \\
\text { UADY }\end{array}$ \\
\hline $\begin{array}{l}\text { Yucatán Tuspana } \\
\text { Hocaba }\end{array}$ & Yucatán & Península de Yucatán & $20^{\circ} 49^{\prime} 08.8^{\prime \prime} \mathrm{N}$ & $89^{\circ} 14^{\prime} 46.9^{\prime \prime} \mathrm{O}$ & $50 \mathrm{MA}$ & KY436870 & $\begin{array}{r}\text { N. Fortuny, Hocabá 3, } \\
\text { UADY }\end{array}$ \\
\hline Yucatán Veracruzana & Yucatán & Península de Yucatán & $20^{\circ} 49^{\prime} 08.8^{\prime \prime} \mathrm{N}$ & $89^{\circ} 14^{\prime} 46.9^{\prime \prime O}$ & $50 \mathrm{MA}$ & KY436885 & $\begin{array}{r}\text { N. Fortuny, Hocabá 18, } \\
\text { UADY }\end{array}$ \\
\hline $\begin{array}{l}\text { Yucatán Tuspena } \\
\text { Hocaba }\end{array}$ & Yucatán & Península de Yucatán & $20^{\circ} 49^{\prime} 08.8^{\prime \prime} \mathrm{N}$ & $89^{\circ} 14^{\prime} 46.9^{\prime \prime} \mathrm{O}$ & $50 \mathrm{MA}$ & KY436886 & $\begin{array}{r}\text { N. Fortuny, Hocabá } 19, \\
\text { UADY }\end{array}$ \\
\hline Jalisco Mansa & Jalisco & Costa del Pacífico & $20^{\circ} 51^{\prime} 30.41^{\prime \prime} \mathrm{N}$ & $103^{\circ} 45^{\prime} 57.22^{\prime \prime O}$ & $52 \mathrm{MA}$ & KY436841 & $\begin{array}{r}\text { M. Ferrer, Tequila 1, } \\
\text { UADY }\end{array}$ \\
\hline Jalisco Obo & Jalisco & Costa del Pacífico & $20^{\circ} 51^{\prime} 30.41^{\prime \prime N}$ & $103^{\circ} 45^{\prime} 57.22^{\prime \prime O}$ & $52 \mathrm{MA}$ & KY436842 & $\begin{array}{r}\text { M. Ferrer, Tequila 2, } \\
\text { UADY }\end{array}$ \\
\hline 286a_hapO & Nayarit & Costa del Pacífico & $21^{\circ} 19^{\prime} 41.3^{\prime \prime} \mathrm{N}$ & $105^{\circ} 11^{\prime} 04.5^{\prime \prime O}$ & $53 \mathrm{~S}$ & DQ163991 & A. Miller $286 a(\mathrm{MO})$ \\
\hline 286b_hapO & Nayarit & Costa del Pacífico & $21^{\circ} 19^{\prime} 41.3^{\prime \prime} \mathrm{N}$ & $105^{\circ} 11^{\prime} 04.5^{\prime \prime O}$ & $53 \mathrm{~S}$ & DQ163992 & A. Miller $286 b(\mathrm{MO})$ \\
\hline Nayarit Nay 18 & Nayarit & Costa del Pacífico & $21^{\circ} 19^{\prime} 41.3^{\prime \prime} \mathrm{N}$ & $105^{\circ} 11^{\prime} 04.5^{\prime \prime O}$ & $53 \mathrm{~S}$ & KY436860 & Nayarit, CRUPY \\
\hline Sinaloa Sin 3 & Sinaloa & Costa del Pacífico & $26^{\circ} 56^{\prime} 41.49^{\prime \prime} \mathrm{N}$ & $108^{\circ} 27^{\prime} 43.24^{\prime \prime O}$ & $54 \mathrm{MA}$ & KY436861 & Rosario, Sinaloa 3, \\
\hline Sinaloa Sin 15 & Sinaloa & Costa del Pacífico & $26^{\circ} 56^{\prime} 41.49^{\prime \prime} \mathrm{N}$ & $108^{\circ} 27^{\prime} 43.24^{\prime \prime O}$ & $54 \mathrm{MA}$ & KY436862 & $\begin{array}{r}\text { CRUPY } \\
\text { Rosario, Sinaloa 15, } \\
\text { CRUPY }\end{array}$ \\
\hline E17_1_hapD & Brasil & ---- & ---- & ---- & Brasil & DQ163957 & A. Costello E17 (NY) \\
\hline E26_1_hapC & Brasil & ---- & ---- & ---- & Brasil & DQ163956 & A. Costello E26 (NY) \\
\hline E3_hapE & Brasil & ---- & ---- & ---- & Brasil & DQ163955 & A. Costello E3 (NY) \\
\hline F10_hapB & Brasil & ---- & ---- & ---- & Brasil & DQ163953 & A. Costello F10 (NY) \\
\hline F12_2_hapC & Brasil & ---- & ---- & ---- & Brasil & DQ163954 & A. Costello F12 (NY) \\
\hline F14_2_hapL & Brasil & ---- & ---- & ---- & Brasil & DQ163984 & A. Costello F14 (NY) \\
\hline F20_hapA & Brasil & ---- & ---- & ---- & Brasil & DQ163952 & A. Costello F20 (NY) \\
\hline R17_1_hapM & Brasil & ---- & ---- & ---- & Brasil & DQ163988 & A. Costello R17 (NY) \\
\hline R7_1_hapN & Brasil & ---- & ---- & ---- & Brasil & DQ163989 & A. Costello R7 (NY) \\
\hline R71_1_hapM & Brasil & ---- & ---- & ---- & Brasil & DQ163987 & A. Costello R71 (NY) \\
\hline R72_2_hapM & Brasil & ---- & ---- & ---- & Brasil & DQ163986 & A. Costello R72 (NY) \\
\hline R73_1_hapL & Brasil & ---- & ---- & ---- & Brasil & DQ163985 & A. Costello R73 (NY) \\
\hline
\end{tabular}


Apéndice 2. Secuencias empleadas en la reconstrucción de los cladogramas con la región intergénica trnA-trnH de cloroplasto (trnA-trnH) y el gen nuclear fosfoenol piruvato carboxilasa $(P E P C)$ para identificar las relaciones entre las especies del género Spondias L. en Mesoamérica. La región incluida en el alineamiento final (Región) se presenta para cada accesión de GenBank. El número de accesión de GenBank e información del voucher (colector, número o clave de colecta, herbario o colección de referencia) del que se obtuvieron las secuencias (tomadas de las referencias en literatura citada) se presentan en las últimas columnas; mientras que en la columna individuo/espécimen se presenta el nombre de la secuencia que se registró en GenBank.

\begin{tabular}{|c|c|c|c|c|c|c|}
\hline Especie & Individuo/Espécimen & Gen & Región & $\begin{array}{l}\text { Accesión } \\
\text { GenBank }\end{array}$ & Referencia & Información de voucher \\
\hline $\begin{array}{l}\text { Bursera arborea (Rose) L. } \\
\text { Riley. }\end{array}$ & Rosell 16 (MEXU) & $P E P C$ & $1-231$ & GQ377934 & De Nova et al., 2012 & J. A. Rosell 16 (MEXU) \\
\hline Bursera arida (Rose) Standl. & $\begin{array}{l}\text { J. C. Montero } 803 \\
\text { (MEXU) }\end{array}$ & PEPC & $1-231$ & JF919098 & De Nova et al., 2012 & $\begin{array}{l}\text { J. C. Montero } 803 \\
\text { (MEXU) }\end{array}$ \\
\hline $\begin{array}{l}\text { Bursera attenuata (Rose) L. } \\
\text { Riley. }\end{array}$ & $\begin{array}{l}\text { R. Medina } 3417 \\
\text { (MEXU) }\end{array}$ & $P E P C$ & $1-231$ & GQ377936 & De Nova et al., 2012 & $\begin{array}{l}\text { R. Medina } 3417 \\
(\mathrm{MEXU})\end{array}$ \\
\hline $\begin{array}{l}\text { Bursera attenuata (Rose) L. } \\
\text { Riley. }\end{array}$ & $\begin{array}{l}\text { R. Medina } 3412 \\
\text { (MEXU) }\end{array}$ & $P E P C$ & $1-231$ & GQ377935 & De Nova et al., 2012 & $\begin{array}{l}\text { R. Medina } 3412 \\
\text { (MEXU) }\end{array}$ \\
\hline $\begin{array}{l}\text { Bursera attenuata (Rose) L. } \\
\text { Riley. }\end{array}$ & $\begin{array}{l}\text { R. Medina } 3423 \\
\text { (MEXU) }\end{array}$ & $P E P C$ & $1-231$ & GQ377937 & De Nova et al., 2012 & $\begin{array}{l}\text { R. Medina } 3423 \\
\text { (MEXU) }\end{array}$ \\
\hline $\begin{array}{l}\text { Bursera brunea (Urb.) Urb. } \\
\text { \& Ekman }\end{array}$ & clone 5 & PEPC & $1-231$ & AY309381 & $\begin{array}{l}\text { Weeks y Simpson, } \\
2004\end{array}$ & $\begin{array}{l}\text { A. Weeks 01-VIII-22-2 } \\
\text { (TEX) }\end{array}$ \\
\hline Bursera discolor Rzed. & Bursera discolor & PEPC & $1-229$ & AY309364 & $\begin{array}{l}\text { Weeks y Simpson, } \\
2004\end{array}$ & $\begin{array}{l}\text { A. Weeks 98-VII-15-1 } \\
\text { (TEX) }\end{array}$ \\
\hline Bursera galeottiana Engl. & $\begin{array}{l}\text { J. C. Montero } 805 \\
\text { (MEXU) }\end{array}$ & PEPC & $1-231$ & JF919117 & De Nova et al., 2012 & $\begin{array}{l}\text { J. C. Montero } 805 \\
\text { (MEXU) }\end{array}$ \\
\hline $\begin{array}{l}\text { Bursera gracilipes Urb. \& } \\
\text { Ekman }\end{array}$ & clone 5 & $P E P C$ & $1-231$ & AY309387 & $\begin{array}{l}\text { Weeks y Simpson, } \\
2004\end{array}$ & A. Veloz 2677 (JBSD) \\
\hline $\begin{array}{l}\text { Bursera gracilipes Urb. \& } \\
\text { Ekman }\end{array}$ & clone 4 & $P E P C$ & $1-231$ & AY309386 & $\begin{array}{l}\text { Weeks y Simpson, } \\
2004\end{array}$ & A. Veloz 2677 (JBSD) \\
\hline $\begin{array}{l}\text { Bursera instabilis McVaugh } \\
\text { \& Rzed. }\end{array}$ & Rosell 12 (MEXU) & PEPC & $1-231$ & GQ377947 & De Nova et al., 2012 & J. A. Rosell 12 (MEXU) \\
\hline $\begin{array}{l}\text { Bursera instabilis McVaugh } \\
\text { \& Rzed. }\end{array}$ & Rosell 11 (MEXU) & PEPC & $1-231$ & GQ377946 & De Nova et al., 2012 & J. A. Rosell 11 (MEXU) \\
\hline $\begin{array}{l}\text { Bursera instabilis McVaugh } \\
\text { \& Rzed. }\end{array}$ & Rosell 13 (MEXU) & $P E P C$ & $1-231$ & GQ377948 & De Nova et al., 2012 & J. A. Rosell 13 (MEXU) \\
\hline Bursera itzae Lundell & $\begin{array}{l}\text { J. C. Montero } 1029 \\
\text { (MEXU) }\end{array}$ & PEPC & $1-231$ & GQ377950 & De Nova et al., 2012 & $\begin{array}{l}\text { J. C. Montero } 1029 \\
\text { (MEXU) }\end{array}$ \\
\hline Bursera itzae Lundell & $\begin{array}{l}\text { J. C. Montero } 1030 \\
\text { (MEXU) }\end{array}$ & PEPC & $1-231$ & GQ377951 & De Nova et al., 2012 & $\begin{array}{l}\text { J. C. Montero } 1030 \\
\text { (MEXU) }\end{array}$ \\
\hline Bursera krusei Rzed. & $\begin{array}{l}\text { R. Medina } 4045 \\
\text { (MEXU) }\end{array}$ & PEPC & $1-231$ & GQ377952 & De Nova et al., 2012 & $\begin{array}{l}\text { R. Medina } 4045 \\
\text { (MEXU) }\end{array}$ \\
\hline $\begin{array}{l}\text { Bursera lancifolia (Schltdl.) } \\
\text { Engl. }\end{array}$ & Bursera lancifolia & PEPC & $1-229$ & AY309368 & $\begin{array}{l}\text { Weeks y Simpson, } \\
2004\end{array}$ & $\begin{array}{l}\text { A. Weeks 98-VII-14-5 } \\
\text { (TEX) }\end{array}$ \\
\hline $\begin{array}{l}\text { Bursera longipes (Rose) } \\
\text { Standl. }\end{array}$ & Cervantes 5 (MEXU) & PEPC & $1-231$ & GQ377955 & De Nova et al., 2012 & A. Cervantes 5 (MEXU) \\
\hline $\begin{array}{l}\text { Bursera longipes (Rose) } \\
\text { Standl. }\end{array}$ & Olson 1028 (MEXU) & PEPC & $1-231$ & GQ377956 & De Nova et al., 2012 & $\begin{array}{l}\text { M. E. Olson } 1028 \\
\text { (MEXU) }\end{array}$ \\
\hline $\begin{array}{l}\text { Bursera longipes (Rose) } \\
\text { Standl. }\end{array}$ & Olson 1029 (MEXU) & PEPC & $1-231$ & GQ377954 & De Nova et al., 2012 & $\begin{array}{l}\text { M. E. Olson } 1029 \\
\text { (MEXU) }\end{array}$ \\
\hline $\begin{array}{l}\text { Bursera longipes (Rose) } \\
\text { Standl. }\end{array}$ & R. Medina P-6 (MEXU) & $P E P C$ & $1-231$ & GQ377957 & De Nova et al., 2012 & R. Medina P-6 (MEXU) \\
\hline
\end{tabular}


Apéndice 2. Continuación.

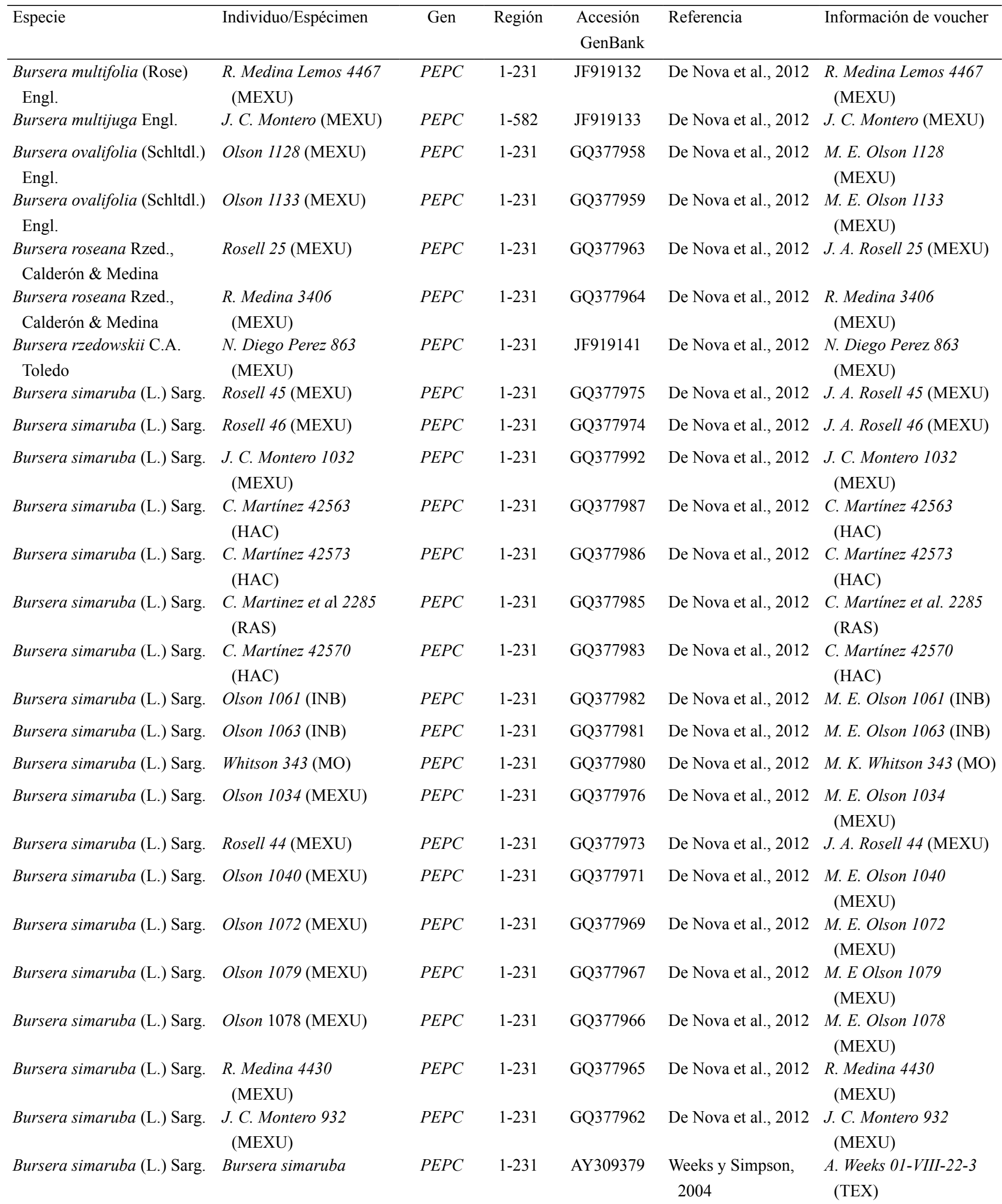


Apéndice 2. Continuación.

\begin{tabular}{|c|c|c|c|c|c|c|}
\hline Especie & Individuo/Espécimen & Gen & Región & $\begin{array}{l}\text { Accesión } \\
\text { GenBank }\end{array}$ & Referencia & Información de voucher \\
\hline Bursera simaruba (L.) Sarg. & $\begin{array}{l}\text { J. C. Montero } 938 \\
\text { (MEXU) }\end{array}$ & $P E P C$ & $1-231$ & GQ377961 & De Nova et al., 2012 & $\begin{array}{l}\text { J. C. Montero } 938 \\
\text { (MEXU) }\end{array}$ \\
\hline Bursera simaruba (L.) Sarg. & $\begin{array}{l}\text { J. C. Montero } 1028 \\
\text { (MEXU) }\end{array}$ & PEPC & $1-231$ & GQ377991 & De Nova et al., 2012 & $\begin{array}{l}\text { J. C. Montero } 1028 \\
\text { (MEXU) }\end{array}$ \\
\hline Canarium balansae Engl. & $\begin{array}{l}\text { Canarium balansae } \\
\text { Engl. }\end{array}$ & $\operatorname{trn} A-\operatorname{trn} H$ & $172-312$ & FJ466486 & Weeks, 2009 & $\begin{array}{l}\text { J. Munzinger } 2965 \\
\text { (NOU) }\end{array}$ \\
\hline $\begin{array}{l}\text { Pseudospondias microcarpa } \\
\text { (A. Rich.) Engl. }\end{array}$ & PM5455 (LBV) & $\operatorname{trn} A-\operatorname{trn} H$ & $156-614$ & KC667979 & $\begin{array}{l}\text { Parmentier et al., } \\
2013\end{array}$ & P. Morgane $5455(\mathrm{LBV})$ \\
\hline $\begin{array}{l}\text { Pseudospondias microcarpa } \\
\text { (A. Rich.) Engl. }\end{array}$ & PM5584 (LBV) & $\operatorname{trn} A-\operatorname{trn} H$ & $151-609$ & KC688827 & $\begin{array}{l}\text { Parmentier et al., } \\
2013\end{array}$ & P. Morgane $5584(\mathrm{LBV})$ \\
\hline Spondias dulcis Parkinson & isolate Spo.dulci 23333 & $\operatorname{trn} A-\operatorname{trn} H$ & $258-645$ & KJ026796 & Machado et al., 2014 & $\begin{array}{l}\text { M. C. Machado } 1574 \\
\text { (HUEFS) }\end{array}$ \\
\hline Spondias dulcis Parkinson & $\begin{array}{l}\text { isolate Spo.dulci } \\
2375.05\end{array}$ & $\operatorname{trn} A-\operatorname{trn} H$ & $258-645$ & KJ026800 & Machado et al., 2014 & $\begin{array}{l}\text { M. C. Machado et al. } \\
1302 \text { (HUEFS) }\end{array}$ \\
\hline Spondias dulcis Parkinson & $\begin{array}{l}\text { isolate Spo.dulci } \\
2375.04\end{array}$ & $\operatorname{trn} A-\operatorname{trn} H$ & $258-645$ & KJ026799 & Machado et al., 2014 & $\begin{array}{l}\text { M. C. Machado et al. } \\
1300 \text { (HUEFS) }\end{array}$ \\
\hline Spondias dulcis Parkinson & $\begin{array}{l}\text { isolate Spo.dulci } \\
2375.03\end{array}$ & $\operatorname{trn} A-\operatorname{trn} H$ & $258-645$ & KJ026798 & Machado et al., 2014 & $\begin{array}{l}\text { M. C. Machado et al. } \\
\text { (HUEFS) }\end{array}$ \\
\hline Spondias dulcis Parkinson & isolate Spo.dulci 23334 & $\operatorname{trn} A-\operatorname{trn} H$ & $258-645$ & KJ026797 & Machado et al., 2014 & $\begin{array}{l}\text { M. C. Machado } 1574 \\
\text { (HUEFS) }\end{array}$ \\
\hline Spondias macrocarpa Engl. & $\begin{array}{l}\text { isolate Spo.macro } \\
2523.03\end{array}$ & $\operatorname{trn} A-\operatorname{trn} H$ & $184-627$ & KJ026803 & Machado et al., 2014 & S. Costa s.n. (HUEFS) \\
\hline Spondias macrocarpa Engl. & $\begin{array}{l}\text { isolate Spo.macro } \\
2443.02\end{array}$ & $\operatorname{trn} A-\operatorname{trn} H$ & $184-627$ & KJ026802 & Machado et al., 2014 & $\begin{array}{l}\text { M. C. Machado } 1550 \\
\text { (HUEFS) }\end{array}$ \\
\hline Spondias macrocarpa Engl. & $\begin{array}{l}\text { isolate Spo.macro } \\
2443.01\end{array}$ & $\operatorname{trn} A-\operatorname{trn} H$ & $184-627$ & KJ026801 & Machado et al., 2014 & $\begin{array}{l}\text { M. C. Machado } 1549 \\
\text { (HUEFS) }\end{array}$ \\
\hline Spondias macrocarpa Engl. & $\begin{array}{l}\text { isolate Spo.macro } \\
2523.05\end{array}$ & $\operatorname{trn} A-\operatorname{trn} H$ & $184-627$ & KJ026804 & Machado et al., 2014 & $\begin{array}{l}\text { H. Lorenzi } 4068 \\
\text { (HUEFS) }\end{array}$ \\
\hline Spondias mombin L. & $\begin{array}{l}\text { isolate Spo.mombi } \\
26064\end{array}$ & $\operatorname{trn} A-\operatorname{trn} H$ & $179-612$ & KJ026814 & Machado et al., 2014 & $\begin{array}{c}\text { M. C. Machado y N. G. } \\
\text { Antas } 1565 \text { (HUEFS) }\end{array}$ \\
\hline Spondias mombin L. & $\begin{array}{l}\text { isolate Spo.mombi } \\
26063\end{array}$ & $\operatorname{trn} A-\operatorname{trn} H$ & $179-612$ & KJ026813 & Machado et al., 2014 & $\begin{array}{c}\text { M. C. Machado y N. G. } \\
\text { Antas } 1565 \text { (HUEFS) }\end{array}$ \\
\hline Spondias mombin L. & $\begin{array}{l}\text { isolate Spo.mombi } \\
26062\end{array}$ & $\operatorname{trn} A-\operatorname{trn} H$ & $179-612$ & KJ026812 & Machado et al., 2014 & $\begin{array}{c}\text { M. C. Machado y N. G. } \\
\text { Antas } 1565 \text { (HUEFS) }\end{array}$ \\
\hline Spondias mombin L. & $\begin{array}{l}\text { isolate Spo.mombi } \\
26061\end{array}$ & $\operatorname{trn} A-\operatorname{trn} H$ & $179-612$ & KJ026811 & Machado et al., 2014 & $\begin{array}{c}\text { M. C. Machado y N. G. } \\
\text { Antas } 1565 \text { (HUEFS) }\end{array}$ \\
\hline Spondias mombin L. & $\begin{array}{l}\text { isolate Spo.mombi } \\
23861\end{array}$ & $\operatorname{trn} A-\operatorname{trn} H$ & $179-612$ & KJ026810 & Machado et al., 2014 & E. Melo et al. (HUEFS) \\
\hline Spondias mombin L. & $\begin{array}{l}\text { isolate Spo.mombi } \\
1717.22\end{array}$ & $\operatorname{trn} A-\operatorname{trn} H$ & $179-612$ & KJ026809 & Machado et al., 2014 & $\begin{array}{l}\text { A. M. Miranda } 4462 \\
\text { (HUEFS) }\end{array}$ \\
\hline Spondias mombin L. & $\begin{array}{l}\text { isolate Spo.mombi } \\
17179\end{array}$ & $\operatorname{trn} A-\operatorname{trn} H$ & $179-612$ & KJ026808 & Machado et al., 2014 & $\begin{array}{l}\text { A. M. Miranda } 4462 \\
\text { (HUEFS) }\end{array}$ \\
\hline Spondias mombin L. & $\begin{array}{l}\text { isolate Spo.mombi } \\
17173\end{array}$ & $\operatorname{trn} A-\operatorname{trn} H$ & $179-612$ & KJ026807 & Machado et al., 2014 & $\begin{array}{l}\text { A. M. Miranda } 4462 \\
\text { (HUEFS) }\end{array}$ \\
\hline Spondias mombin L. & $\begin{array}{l}\text { isolate Spo.mombi } \\
17171\end{array}$ & $\operatorname{trn} A-\operatorname{trn} H$ & $179-612$ & KJ026806 & Machado et al., 2014 & $\begin{array}{l}\text { A. M. Miranda } 4462 \\
\text { (HUEFS) }\end{array}$ \\
\hline Spondias mombin L. & $\begin{array}{l}\text { isolate Spo.mombi } \\
1717.04\end{array}$ & $\operatorname{trn} A-\operatorname{trn} H$ & $179-612$ & KJ026805 & Machado et al., 2014 & $\begin{array}{l}\text { A. M. Miranda } 4462 \\
\text { (HUEFS) }\end{array}$ \\
\hline
\end{tabular}


Apéndice 2. Continuación.

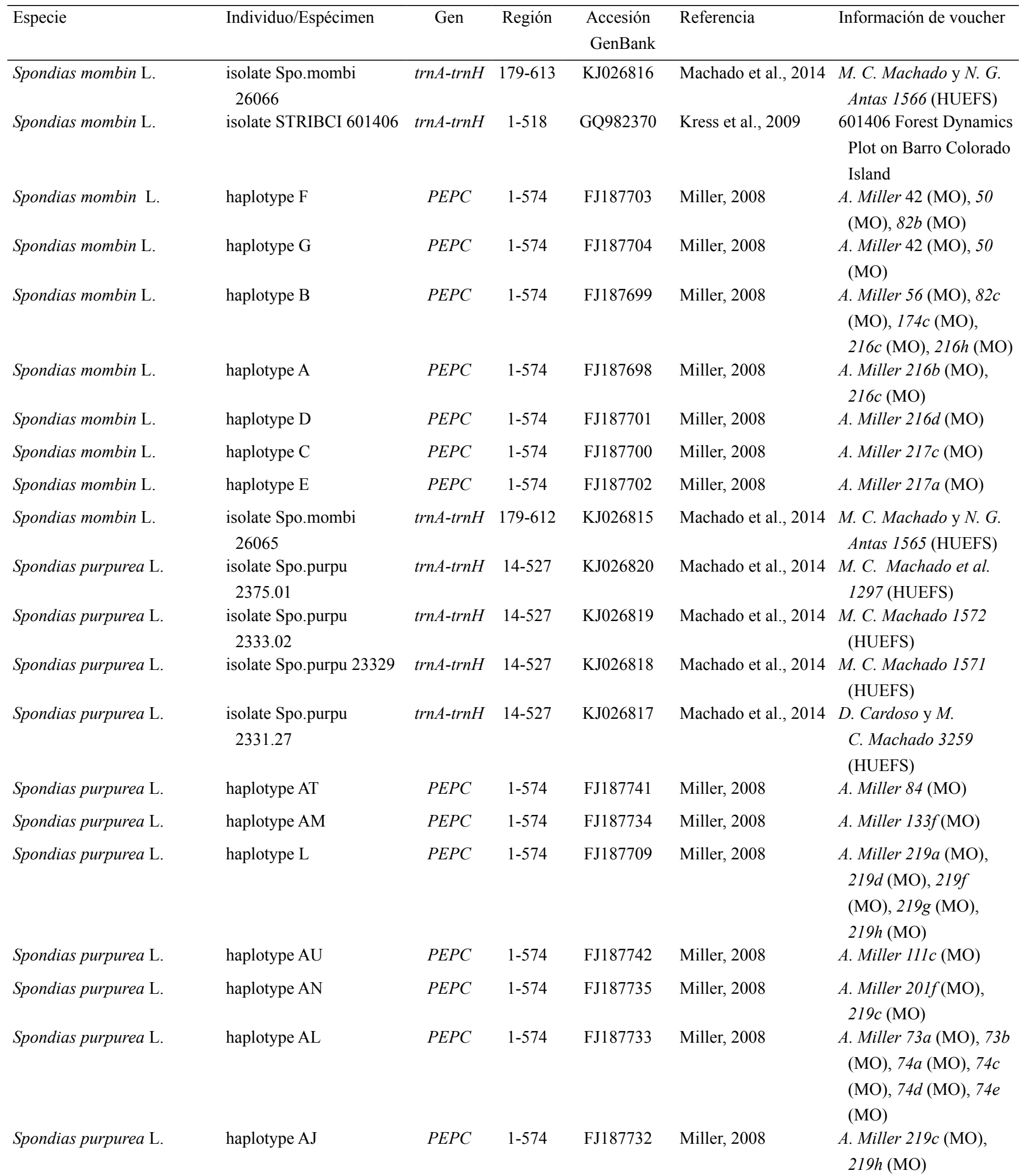


Apéndice 2. Continuación.

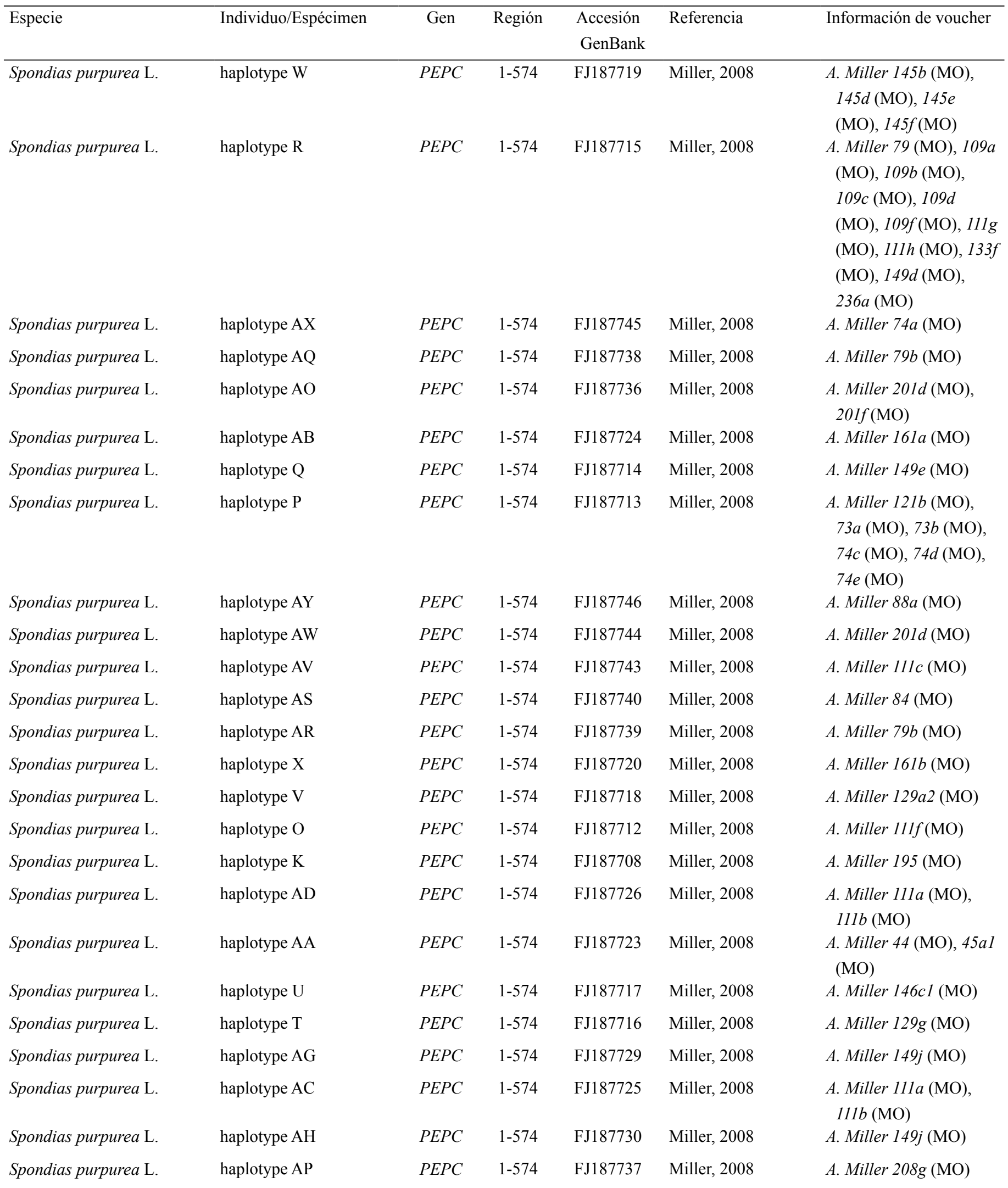


Apéndice 2. Continuación.

\begin{tabular}{|c|c|c|c|c|c|c|}
\hline Especie & Individuo/Espécimen & Gen & Región & $\begin{array}{l}\text { Accesión } \\
\text { GenBank }\end{array}$ & Referencia & Información de voucher \\
\hline Spondias purpurea L. & haplotype AE & $P E P C$ & $1-574$ & FJ187727 & Miller, 2008 & A. Miller $146 f 1(\mathrm{MO})$ \\
\hline Spondias purpurea L. & haplotype Z & $P E P C$ & $1-574$ & FJ187722 & Miller, 2008 & A. Miller $43(\mathrm{MO})$ \\
\hline Spondias purpurea L. & haplotype AF & $P E P C$ & $1-574$ & FJ187728 & Miller, 2008 & A. Miller $146 f 1(\mathrm{MO})$ \\
\hline Spondias purpurea L. & haplotype Y & $P E P C$ & $1-574$ & FJ187721 & Miller, 2008 & $\begin{array}{l}\text { A. Miller } 41(\mathrm{MO}), 45 a 1 \\
(\mathrm{MO})\end{array}$ \\
\hline Spondias purpurea L. & haplotype AI & $P E P C$ & $1-574$ & FJ187731 & Miller, 2008 & A. Miller $174 c(\mathrm{MO})$ \\
\hline Spondias purpurea L. & haplotype $\mathrm{H}$ & $P E P C$ & $1-574$ & FJ187705 & Miller, 2008 & A. Miller $82 b(\mathrm{MO})$ \\
\hline Spondias purpurea L. & haplotype N & $P E P C$ & $1-574$ & FJ187711 & Miller, 2008 & A. Miller 129al (MO) \\
\hline Spondias purpurea L. & $\begin{array}{l}\text { isolate Spo.purpu } \\
2375.02\end{array}$ & $\operatorname{trn} A$-trnH & $14-527$ & KJ026821 & Machado et al., 2014 & $\begin{array}{l}\text { M. C. Machado et al. } \\
1299 \text { (HUEFS) }\end{array}$ \\
\hline Spondias purpurea L. & haplotype J & $P E P C$ & $1-574$ & FJ187707 & Miller, 2008 & $\begin{array}{l}\text { A. Miller } 129 f 1(\mathrm{MO}) \text {, } \\
\text { 145h (MO), } 146 d \\
(\mathrm{MO})\end{array}$ \\
\hline Spondias purpurea L. & haplotype I & $P E P C$ & $1-574$ & FJ187706 & Miller, 2008 & A. Miller 82c (MO) \\
\hline Spondias purpurea L. & haplotype M & $P E P C$ & $1-574$ & FJ187710 & Miller, 2008 & A. Miller 129f2 (MO) \\
\hline $\begin{array}{l}\text { Spondias radlkoferi Donn. } \\
\text { Sm. }\end{array}$ & haplotype AZ & $P E P C$ & $1-624$ & FJ187747 & Miller, 2008 & A. Miller $49(\mathrm{MO})$ \\
\hline $\begin{array}{l}\text { Spondias venulosa (Engl.) } \\
\text { Engl. }\end{array}$ & $\begin{array}{l}\text { isolate Spo.venul } \\
2606.06\end{array}$ & $\operatorname{trn} A-\operatorname{trn} H$ & $187-584$ & KJ026840 & Machado et al., 2014 & $\begin{array}{l}\text { M. C. Machado y N. G. } \\
\text { Antas } 1570 \text { (HUEFS) }\end{array}$ \\
\hline $\begin{array}{l}\text { Spondias venulosa (Engl.) } \\
\text { Engl. }\end{array}$ & $\begin{array}{l}\text { isolate Spo.venul } \\
2606.05\end{array}$ & $\operatorname{trn} A-\operatorname{trn} H$ & $187-584$ & KJ026839 & Machado et al., 2014 & $\begin{array}{l}\text { M. C. Machado y N. G. } \\
\text { Antas } 1570 \text { (HUEFS) }\end{array}$ \\
\hline $\begin{array}{l}\text { Spondias venulosa (Engl.) } \\
\text { Engl. }\end{array}$ & $\begin{array}{l}\text { isolate Spo.venul } \\
2606.04\end{array}$ & $\operatorname{trn} A-\operatorname{trn} H$ & $187-584$ & KJ026838 & Machado et al., 2014 & $\begin{array}{l}\text { M. C. Machado y N. G. } \\
\text { Antas } 1570 \text { (HUEFS) }\end{array}$ \\
\hline $\begin{array}{l}\text { Spondias venulosa (Engl.) } \\
\text { Engl. }\end{array}$ & $\begin{array}{l}\text { isolate Spo.venul } \\
2606.03\end{array}$ & $\operatorname{trn} A$-trnH & $187-584$ & KJ026837 & Machado et al., 2014 & $\begin{array}{l}\text { M. C. Machado y N. G. } \\
\text { Antas } 1568 \text { (HUEFS) }\end{array}$ \\
\hline $\begin{array}{l}\text { Spondias venulosa (Engl.) } \\
\text { Engl. }\end{array}$ & $\begin{array}{l}\text { isolate Spo.venul } \\
2606.02\end{array}$ & $\operatorname{trn} A-\operatorname{trn} H$ & $187-584$ & KJ026836 & Machado et al., 2014 & $\begin{array}{l}\text { M. C. Machado y N. G. } \\
\text { Antas } 1568 \text { (HUEFS) }\end{array}$ \\
\hline $\begin{array}{l}\text { Spondias venulosa (Engl.) } \\
\text { Engl. }\end{array}$ & $\begin{array}{l}\text { isolate Spo.venul } \\
2606.01\end{array}$ & $\operatorname{trn} A-\operatorname{trn} H$ & $187-584$ & KJ026835 & Machado et al., 2014 & $\begin{array}{l}\text { M. C. Machado y N. G. } \\
\text { Antas } 1568 \text { (HUEFS) }\end{array}$ \\
\hline $\begin{array}{l}\text { Spondias venulosa (Engl.) } \\
\text { Engl. }\end{array}$ & $\begin{array}{l}\text { isolate Spo.venul } \\
2446.07\end{array}$ & $\operatorname{trn} A-\operatorname{trn} H$ & $187-584$ & KJ026834 & Machado et al., 2014 & $\begin{array}{l}\text { M. C. Machado y F. X. } \\
\text { Souza } 1560 \text { (HUEFS) }\end{array}$ \\
\hline $\begin{array}{l}\text { Spondias venulosa (Engl.) } \\
\text { Engl. }\end{array}$ & $\begin{array}{l}\text { isolate Spo.venul } \\
2446.06\end{array}$ & $\operatorname{trn} A-\operatorname{trn} H$ & $187-584$ & KJ026833 & Machado et al., 2014 & $\begin{array}{l}\text { M. C. Machado y F. X. } \\
\text { Souza } 1559 \text { (HUEFS) }\end{array}$ \\
\hline $\begin{array}{l}\text { Spondias venulosa (Engl.) } \\
\text { Engl. }\end{array}$ & isolate Spo.venul 22381 & $\operatorname{trn} A-\operatorname{trn} H$ & $187-584$ & KJ026832 & Machado et al., 2014 & $\begin{array}{l}\text { M. C. Machado } 1283 \\
\text { (HUEFS) }\end{array}$ \\
\hline $\begin{array}{l}\text { Spondias venulosa (Engl.) } \\
\text { Engl. }\end{array}$ & $\begin{array}{l}\text { isolate Spo.venul } \\
2238.07\end{array}$ & $\operatorname{trn} A-\operatorname{trn} H$ & $187-584$ & KJ026831 & Machado et al., 2014 & $\begin{array}{l}\text { M. C. Machado } 1278 \\
\text { (HUEFS) }\end{array}$ \\
\hline $\begin{array}{l}\text { Spondias venulosa (Engl.) } \\
\text { Engl. }\end{array}$ & $\begin{array}{l}\text { isolate Spo.venul } \\
2606.07\end{array}$ & $\operatorname{trn} A-\operatorname{trn} H$ & $187-584$ & KJ026841 & Machado et al., 2014 & $\begin{array}{c}\text { M. C. Machado y N. G. } \\
\text { Antas } 1570 \text { (HUEFS) }\end{array}$ \\
\hline
\end{tabular}

